\title{
Expressividade na teoria de Mathis Lussy: dinâmica e agógica em performances violonísticas
}

\author{
Expressiveness in Mathis Lussy's theory: \\ dynamic and agogic in guitar performances
}

Felipe Augusto Vieira da Silva

Universidade Estadual do Paraná - FAP

\section{Rodolfo Coelho Nogueira da Souza}

Universidade de São Paulo

\begin{abstract}
Resumo: o trabalho tem como objetivo abordar alguns dos principais conceitos da teoria dos acentos de Mathis Lussy a partir de uma perspectiva contemporânea. A primeira parte do texto trata dos fundamentos da teoria lussyana relacionados à natureza epistemológica da expressão, à busca por uma teoria da expressividade e à união entre teoria e performance musical. A segunda parte consiste na análise da obra Adelita, de Tárrega, utilizando os princípios lussyanos de análise da expressividade musical. Como fonte de dados recorremos à partitura da obra e a performances registradas em áudio. Os resultados indicam a proximidade entre os métodos de Lussy e as abordagens contemporâneas de pesquisas sobre expressividade musical. Desse modo, o estudo da obra de Lussy demonstra que ele foi um pioneiro da linha de pesquisa hoje chamada de musicologia empírica.
\end{abstract}

Palavras-chave: Mathis Lussy; expressão e expressividade musical; análise de performance; Tárrega.

\begin{abstract}
This article aims to address some of the main concepts of Mathis Lussy accent theory from a contemporary perspective. The first part of the text deals with the foundations of Lussy's theory related to the epistemological nature of expression, the search for a theory of expressiveness and the union between theory and musical performance. The second part consists of the analysis of Tárrega's work Adelita, using the lussian principles of expressiveness analysis. As data sources, we use the score of the work and expert performances recorded in audio. The results indicate the proximity between Lussy's methods and the contemporary research approaches to music expression. This way, the study of Lussy's works demonstrate that he was a pioneer of the research field nowadays called empirical musicology.
\end{abstract}

Keywords: Mathis Lussy; musical expression and expressivity; analysis of performance; Tárrega. 


\section{Introdução}

Os estudos sobre expressividade na performance musical tiveram um desenvolvimento mais profícuo na segunda metade do século XX, obviamente propiciado pela revolução tecnológica desse período. A preocupação dessa abordagem vai além da partitura como objeto de pesquisa, adicionando nessa equação a própria performance, ao vivo ou gravada, como fonte de dados. Essa linha de pesquisa também se apropria de recursos digitais, como softwares de extração de dados cada vez mais precisos, e por conta disso um corpus metodológico tem sido criado, como foi demonstrado no Empirical Musicology, organizado por Eric Clarke e Nicholas Cook (2004). A principal vantagem desse método está em obter dados a partir de fontes de performances em que várias dimensões estão em plena interação, por exemplo, melodia e acentuação, harmonia e timbre, dinâmica e agógica.

Embora pesquisas dessa natureza tenham se tornado mais comuns após o surgimento da música gravada, as bases para esse tipo de abordagem nos remetem à segunda metade do século XIX com o pioneirismo do teórico francosuiço Mathis Lussy. Entre suas publicações se destacam o Traité de l'expression musicale (1874), Le rythme musical: son origine, sa fonction et son accentuation (1885) e L'anacrouse dans la musique moderne (1903).

Lussy provavelmente foi o primeiro a fazer comparações entre performances com intuito de estabelecer padrões interpretativos. Dentre as fontes de escuta que analisou estão Anton Rubinstein (1829-1894), Hans von Bülow (1829-1894) e Karl Klindworth (1830-1916). Como afirmam Repp (1992) e Dogantan (2002), os trabalhos de Lussy foram as primeiras pesquisas empíricas, ainda que apenas qualitativas, sobre expressividade em performances.

\section{Expressão e Expressividade}

Embora o prestígio de Mathis Lussy, que foi grande durante sua vida, tenha declinado ao longo dos anos, tornando-o uma figura algo secundária na história da teoria musical, suas contribuições para o campo da teoria da performance são inegáveis e tendem a ser recuperadas com o renascimento atual desse campo de pesquisa. Ele foi um dos primeiros a buscar a desvinculação da expressão musical do ideal romântico da performance. Nesse contexto a expressão era vista como "produto da alma" do artista. Lussy foi ousado ao dar 
MUSICA THEORICA Revista da Associação Brasileira de Teoria e Análise Musical 2018, v. 3, n. 2, p. 227-257 - Journal of the Brazilian Society for Music Theory and Analysis@ TeMA 2018 - ISSN 2525-5541

um "grito hanslickiano" em direção a uma maior objetividade nas relações entre expressão e performance. Em consequência disso, sua teoria forçou a expressão a sair do domínio das paixões e caminhar em direção ao domínio da razão.

Ele inicia seu Traité de l'expression musicale (1874) desmistificando a figura do gênio, tão caro ao romantismo alemão, como sendo o único dotado da verdadeira expressão. Em suas palavras "apenas a expressão, a alma da música, ainda permanecia um privilégio natural de poucos dotados" (Lussy 1874, p. i). E, fiel ao ideal positivista de educação para as massas, advoga que todos podem aprender a tocar com expressão desde que recorram à razão como fonte de seu aprendizado.

No entanto, observamos que seu entendimento de expressão musical era bastante peculiar para o período, pois o termo "expressão" ainda remetia ao domínio do intangível, le sentiment, the feelings, das Gefühl. Isso pode ser conferido na recepção de sua obra pela Royal Musical Association, em 1878. Nessa ocasião, houve uma mesa redonda sobre o Traité de l'expression musicale (1874) em que presidente da mesa inicia dizendo:

Todos os músicos mexem suas cabeças com a noção de reduzir a regras coisas intangíveis como a expressão. Então eles dirão, nós podemos mostrar a uma pessoa como amar? Ou como transmitir sentimentos ao que ela executa? É claro que há muita verdade nesses questionamentos, mas vamos tentar abrandar por enquanto nossos preconceitos e escutar o que M. Lussy tem a dizer (Curwen 1878, p. 27).

De fato, no transcorrer da discussão fica claro o equívoco no entendimento da obra de Lussy. A expressão para a maioria de seus contemporâneos diz respeito ao efeito produzido sobre o ouvinte, equiparando-se com sentimentos do tipo amor e ódio. $\mathrm{Ou}$, como disse um dos participantes: a real expressão não pode ser ensinada (Curwen 1878). Fica evidente que o termo expressão foi mal interpretado até porque não havia uma coesão nessa definição. Por conta disso, o termo remetia, e nos remete ainda hoje, a diversas matizes de significação, da estética à comunicação na performance.

Por conta disso, houve a necessidade de redefinir o termo expressão na medida em que o intérprete foi ganhando autonomia artística nos séculos XIX e XX. Mathis Lussy parece contribuir para essa redefinição, haja vista que ele defendeu o caráter pragmático e objetivo da expressão. Para ele "está claro que a causa da expressão musical reside e deve ser encontrada nas notas da estrutura 
da frase musical" (Lussy 1882, p. 2), desse modo a expressão é algo que pode ser discutido de maneira objetiva.

O deslocamento no entendimento da expressão musical foi necessário para que ele passasse a utilizar novas fontes de dados para pesquisas em música, tais como: edições de partituras, fac-símiles e principalmente performances ao vivo. O propósito almejado por ele era a sistematização de uma prática comum dos performers de seu tempo para aspectos como agrupamento, fraseado, dinâmica, agógica e andamento.

Frente a essas duas perspectivas da expressão, a primeira ligada a estética e a segunda ligada à performance, chegamos à divisão dos termos em expressão e expressividade. A expressão possui um amplo espaço para debate que engloba teóricos como Charles Batteux, Michel Chabanon, J. J. Rousseau, K. W. Schlegel, entre outros. ${ }^{1}$ Do lado da expressividade, teóricos como Mathis Lussy, Hugo Riemann, Rudolf Westphal, André Mocquerou, contribuíram para uma teoria da expressividade na performance.

Nos anos 80, com o avanço das tecnologias de extração de dados, pesquisas importantes referentes à expressividade na performance têm sido realizadas e protagonizadas por Todd (1985), Gabrielsson (1987) e Repp (1990), mas só recentemente houve a tentativa de definir as linhas gerais da expressividade. Fabian et al, (2014) reuniram pesquisadores de várias áreas para tentar obter os limites da expressividade, e estabelecem as seguintes proposições:

Expressividade: 1) refere-se ao efeito dos parâmetros auditivos na performance musical (volume, intensidade, frases, tempo, espectro de frequência, etc.) - cobrindo fatores acústicos, psicoacústicos e/ou musicais; 2) refere-se à variação dos parâmetros auditivos longe de uma performance prototípica, mas dentro de restrições estilísticas (por exemplo, muita variação é inaceitável e não está dentro da gama de expressividade); 3) é usado no sentido intransitivo do verbo (nenhuma emoção, humor ou sentimento está necessariamente sendo expressado, no entanto, a performance da música soa "expressiva" em diferentes graus) (Fabian et al 2014, p. xxi).

Isso parece também a preocupação de Lussy em seus escritos: a construção de uma teoria expressiva em música afastada de uma teoria das emoções. A definição de Fabian et al (2014) parece coerente com o ideal lussyano em que a expressividade é entendida como os performers "acentuam, aceleram e alargam,

\footnotetext{
${ }^{1}$ Muitos desses escritos sobre estética podem ser encontrados, traduzidos para o inglês, em Huray, P.; Day, J. (1981).
} 
MUSICA THEORICA Revista da Associação Brasileira de Teoria e Análise Musical 2018, v. 3, n. 2, p. 227-257 - Journal of the Brazilian Society for Music Theory and Analysis@ TeMA 2018 - ISSN 2525-5541

colocam poder e intensidade" (Lussy 1882, p. 3). E por fim, é coerente pois para Lussy a variabilidade de performances em "maior ou menor grau de delicadeza, virtuosidade" é aceita, e observa que intérpretes de seu tempo como Malibran e Frezzolini, "cantam a mesma peça de maneira diametralmente oposta" (Lussy 1874, p. 2), no entanto, dentro dos parâmetros estilísticos.

\section{Lussy e a musicologia empírica}

Dois aspectos unificam a teoria de Lussy e as abordagens contemporâneas da expressividade: as performances como fontes de dados e a estreita relação da performance com a psicologia. Ambos os estudos compõem a chamada Musicologia Empírica, conforme definida por Clarke e Cook.

A musicologia empírica, para resumir, pode ser pensada como a musicologia que implica uma consciência em princípio tanto do potencial para se envolver com grande corpo de dados relevantes, quanto dos métodos apropriados para alcançar isso. A adoção desse termo não nega a dimensão empiricamente evidente de toda a musicologia, mas chama a atenção para o potencial de uma série de abordagens empíricas para a música que ainda não está amplamente disseminada dentro da disciplina (Clarke e Cook 2004, p. 5).

Os escritos de Lussy voltam à cena 80 anos após sua morte, através do artigo de Repp (1992). Naquele texto o Traité foi reconhecido como a primeira pesquisa empírica, ainda que qualitativa, em performance. A mesma avaliação é seguida por Mine Dogantan (2012) que evidencia o pioneirismo de Lussy em pesquisas empíricas sobre expressividade.

Segundo Clarke e Cook (2004, p. 12) as abordagens da musicologia empírica envolvem a geração de dados aplicados em princípios gerais, a observação em torno das condições em que são coletadas, do tipo de controle necessário para a identificação e representação desses dados analíticos em condições ideais. Os dados empíricos podem ser extraídos de fontes tais como partituras, gravações, performances MIDI, vídeos, diários de performers, compositores e ouvintes, entrevistas e questionários.

Sem pretender fazer uma discussão da natureza epistemológica abordada por Clarke e Cook (2004), partimos do princípio de que há uma forte conexão entre a teoria de Lussy e as abordagens contemporâneas da musicologia empírica. Duas qualidades presentes nas pesquisas sobre performances na atualidade - performance como fontes de dados e relações com a psicologia - 
estão o âmago da teoria lussyana. Desse modo, a aplicação atualizada de sua teoria é bastante possível e pode se beneficiar do uso das novas tecnologias de extração de dados.

\section{A teoria expressiva lussyana: Acento e Acentuação}

Um dos aspectos interessantes que fazem do Traité de l'expression musicale (Lussy 1874) um importante auxílio aos intérpretes é a sua integração entre a teoria analítica e performance. Sua ideia de construir uma teoria expressiva passa primeiramente pelo deslocamento da expressão do sentimento para a expressão da razão. Dessa forma, as próximas gerações de instrumentistas poderiam ser educadas pelos esforços teórico e técnico-instrumental.

Nosso trabalho se limita a descobri-los, classificá-los e formulá-los. Por essas descobertas, apesar da imperfeição de nosso ensaio, a lacuna que apontamos no ensino está sendo preenchida; a experiência particular dá lugar aos processos científicos, a expressão musical deixa o domínio exclusivo do sentimento e entra no da razão. (Lussy 1874, p. iii)

Para essa conexão entre teoria e performance Lussy utilizou de maneira distinta os termos acento e acentuação. Isso faz sentido na medida em que os termos são empregados para diferenciar o que é analítico do que é performático (técnico-instrumental), ou, do que é o domínio da expressão e da expressividade. Por exemplo, ele estabelece três categorias de acentos e os relaciona com aspectos psicológicos que engendram a expressão (vide Tabela 1).

\begin{tabular}{|c|c|c|c|}
\hline & \multicolumn{3}{|c|}{ ACENTOS MUSICAIS } \\
\hline & ACENTO MÉTRICO & ACENTO RÍTMICO & $\begin{array}{l}\text { ACENTO EXPRESSIVO } \\
\text { (PATÉTICO) }\end{array}$ \\
\hline Características & $\begin{array}{l}\text { Traz força periódica } \\
\text { marcada por } \\
\text { acentuação dinâmica }\end{array}$ & $\begin{array}{l}\text { Grupos ou padrões } \\
\text { de divisão temporal }\end{array}$ & $\begin{array}{c}\text { Irregularidade, assimetria, } \\
\text { desvio da norma }\end{array}$ \\
\hline Percepção/Ouvinte & $\begin{array}{l}\text { Gera sensação de } \\
\text { regularidade }\end{array}$ & $\begin{array}{l}\text { Gera o sentimento de } \\
\text { arranjo simétrico de } \\
\text { notas que produzem } \\
\text { agrupamentos }\end{array}$ & $\begin{array}{l}\text { Gera algo inesperado ou } \\
\text { surpreendente }\end{array}$ \\
\hline $\begin{array}{l}\text { Relação com } \\
\text { fatores } \\
\text { psicológicos }\end{array}$ & Pertence ao instinto & $\begin{array}{l}\text { Pertence ao domínio } \\
\text { da inteligência }\end{array}$ & Pertence ao sentimento ${ }^{2}$ \\
\hline
\end{tabular}

Tabela 1: Síntese dos acentos que engendram expressão (adaptado de Lussy 1874)

\footnotetext{
${ }^{2} \mathrm{O}$ termo aqui é utilizado no contexto da excitação dos sentimentos, de modo muito similar às teorias da expectativa como a de David Huron (2006).
} 
A primeira fase da teoria expressiva lussyana consiste no processo analítico dos acentos. Isso nada mais é do que a demarcação, no texto musical, das ocorrências dos acentos métrico, rítmico e expressivo. Esses acentos levam em conta a regularidade métrica, os agrupamentos rítmicos, os deslocamentos métricos causados por síncopas, além de outros efeitos similares.

A segunda etapa da teoria expressiva é o processo das acentuações no ato da performance. Elas estão no âmbito técnico-instrumental e se manifestam de duas maneiras: como acentuação agógica ou como acentuação dinâmica. Podem eventualmente acontecer simultaneamente.

Assim podemos concluir que: 1) Para construir sua teoria expressiva Lussy precisou deslocar a ênfase no conceito de expressão para o conceito de razão; 2) Propôs a materialização da expressão (agora expressividade) para que pudesse ser submetida à teoria e análise; 3) Propôs uma divisão entre acento e acentuação, a primeira sendo analítica e a segunda técnico-instrumental; 4) Criou uma metodologia empírica de análise da (e também para a) performance musical que trabalha sobre padrões estilísticos.

Para completar, as tecnologias atuais de análise de gravações e extração de dados podem recuperar a atualidade da teoria lussyana ao gerar novos modelos de pensamentos analíticos na teoria da performance.

\section{Critérios metodológicos: extração de dados em performances para violão e a teoria lussyana}

Há duas fontes principais que podem fornecer dados de performances: gravações e instrumentos MIDI. A extração de dados via protocolo MIDI em pesquisas sobre performance tem sido utilizada quase que exclusivamente na produção pianística. Nesse contexto, Clarke (2004, p.80) diz que esse formato pode codificar dados como: a identificação de qualquer tonalidade atingida; o momento em que uma nota começa; o momento em que uma nota termina; a velocidade da tecla pressionada ou do martelo do piano quando ela atinge a corda (que está diretamente correlacionada com a intensidade do som produzido); o momento em que o pedal está pressionado; o momento em que o pedal é liberado. Sua vantagem é que fornece informações bastante precisas sobre esses procedimentos devido à codificação direta entre processo mecânico e transformação digital, sem perder qualidade na conversão. Há algumas limitações em todo esse processo pois os parâmetros que ele pode captar são 
definidos a priori no algoritmo de conversão, portanto limitados a parâmetros já pré-estabelecidos.

Por outro lado, a extração de dados a partir de uma performance gravada precisa de softwares específicos para esse propósito e a grande vantagem é que permitem abordar tanto gravações históricas quanto contemporâneas, olhando para o material acústico como fruto de um pensamento único, estilísticogeográfico ou de determinada época (obviamente a partir do surgimento da gravação). O grande problema é que ao extrair os dados da gravação os dados podem não ser tão precisos pois demandam muita intervenção do analista. Por exemplo, para extração de fatores rítmicos temos duas formas disponíveis: algoritmos de detecção e demarcação mecânica.

Os algoritmos são extensões dos softwares que carregam uma sequência de procedimentos para a detecção de inter-onset interval (IOI). O problema é que esses algoritmos ainda possuem muitas falhas ou detectam ataques inexistentes. Mas alguns algoritmos, a exemplo dos detectores de variação dinâmica, possuem precisão razoável podendo gerar dados confiáveis. Já as demarcações dos onsets dependem de que o pesquisador indique sua localização manualmente para o software, o que exige uma certa atenção auditiva, caso contrário haverá erros na extração de dados.

No que diz respeito ao violão, certamante há poucos trabalhos que abordam gravações violonísticas como fonte de extração. ${ }^{3} \mathrm{O}$ único que conhecemos se dedica à análise do processamento de sinais. E no que se refere a dados via MIDI não há registros de pesquisas, mesmo que nos últimos anos tenham se desenvolvidos tecnologias de captação digital bastante apuradas para o instrumento.

Essas questões representam ao menos duas dificuldades para análise de performances violonísticas: os algoritmos disponíveis parecem ser ineficientes para o instrumento pois não localizamos algum que esteja preparado para atender as especificidades do violão; a segunda é que não há parâmetros definidos para análise do sinal acústico que abordem tanto as características sonoras quanto técnico-instrumentais. Por exemplo: numa situação de arpejo como devemos marcar dados como o onset?

\footnotetext{
3 Até o momento desconhecemos trabalhos dessa natureza. Há um trabalho (Freire et al. 2012) que estudou o nível de sincronicidade dos acordes plaqués, mas seus resultados são voltados aos estudos da sonologia.
} 
MUSICA THEORICA Revista da Associação Brasileira de Teoria e Análise Musical 2018, v. 3, n. 2, p. 227-257 - Journal of the Brazilian Society for Music Theory and Analysis@ TeMA 2018 - ISSN 2525-5541

Visto isso, escolhemos abordar gravações como fonte de dados obtendoos a partir do software denominado Sonic Visualiser. ${ }^{4}$ Os dados obtidos são referentes à variação dinâmica e variação temporal e, em alguns casos, o perfil melódico. Para cada um desses parâmetros utilizamos ou um Vamp plugin ou um sistema manual; para a dinâmica utilizamos o plugin Loudness desenvolvido por Chris Cannam e Jamie Bullock; 5 para a variação temporal utilizamos o sistema manual de indicação de onsets em que podemos auditivamente determinar os ataques a partir do teclado do computador. No entanto, para ter precisão utilizamos um espectrograma fornecido pelo próprio software para visualizar os eventos e auxiliar a audição (Figura 1).

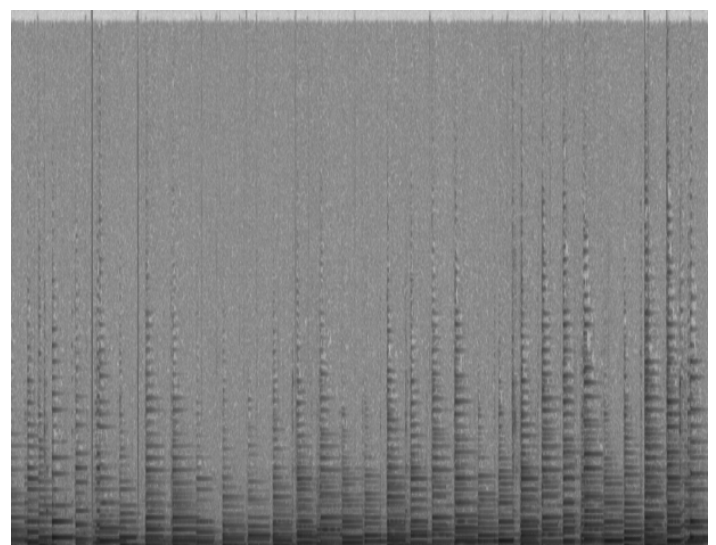

Figura 1: Exemplo de espectrograma para determinação de IOI manualmente

A análise visou estabelecer relações entre a teoria de Lussy e performances violonísticas. Não obstante, pela falta de trabalhos e técnicas para extração de dados violonísticos buscamos relacionar as categorias de acentos lussyanos aos aspectos idiossincráticos. Por exemplo, como visualizar no espectrograma a utilização de acentuação feita com a técnica de apoio? Para resolver isso fizemos alguns experimentos gravando o violão para observar como o espectro reagiria à técnica, desse modo estabelecemos sua indicação nessa análise referencial.

No que se refere a escolha da obra, primeiramente optamos por uma obra do repertório contemporâneo a Lussy e que pertença a um compositor do cânone

${ }^{4}$ O Sonic Visualiser é um software Livre desenvolvido pelo Centro de Música Digital da Queen Mary, Universidade de Londres. Distribuído sob a Licença Pública Geral GNU e disponível para Linux, OS / X e Windows. Disponível em: https://www.sonicvisualiser.org/index.html.

5 Vamp é um sistema de processamento de áudio para plugins que extraem informações descritivas de dados de áudio - normalmente referidos como plugins de análise de áudio ou plugins de extração de recursos de áudio. Disponível em: https://code.soundsoftware.ac.uk /projects/vamp-libxtract-plugins. 
violonístico. Em segundo lugar, escolhemos a peça por critérios como curta duração, andamentos moderados e que tenham gravações disponíveis. Em relação à escolha das gravações nós estabelecemos três performances como fonte de dados, e houve apenas dois critérios para a escolha delas: performances de experts, ou seja, performances realizadas por profissionais e intérpretes muito conhecidos; e o segundo foi selecionar performers de épocas diferentes, como Andrés Segovia (1893-1987) e Juliam Bream (1933-), para observar diferenças estilísticas ocasionadas pelo contraste geracional.

Os gráficos (como na Figura 2) possuem dois parâmetros: a linha dinâmica indicando a energia dos ataques (amarela) e a linha de flutuação temporal (vermelho). Na linha amarela (dinâmica) quanto maior o ataque dinâmico maior é o pico da onda. Já na linha vermelha (agógica) se houver desaceleração do andamento médio, a linha segue em direção descendente, e se houver aceleração, a direção é ascendente. Na coluna esquerda temos a indicação das unidades de medida decibéis e bpms (batidas por minuto), mas sem a parametrização exata de cada uma delas, pois a finalidade é verificar a variação interna dos trechos musicais. Ainda nessa coluna colocamos o andamento médio escolhido pelo performer. Na linha inferior, abaixo da figura, há a demarcação dos compassos e suas subdivisões em pulsos: 1, 1.2 e 1.3 .

Já no interior do gráfico nós dividimos a análise em dois níveis: a parte inferior representa os acentos métrico, rítmico e expressivo; e na região superior os dois símbolos que representam as acentuações dinâmica e agógica. Os acentos demonstram as estruturas que devem ou não ser acentuadas, como também a acentuação que demonstra como os performers dão proeminência para essas notas no discurso. A Tabela 2 faz o resumo dessas simbologias.

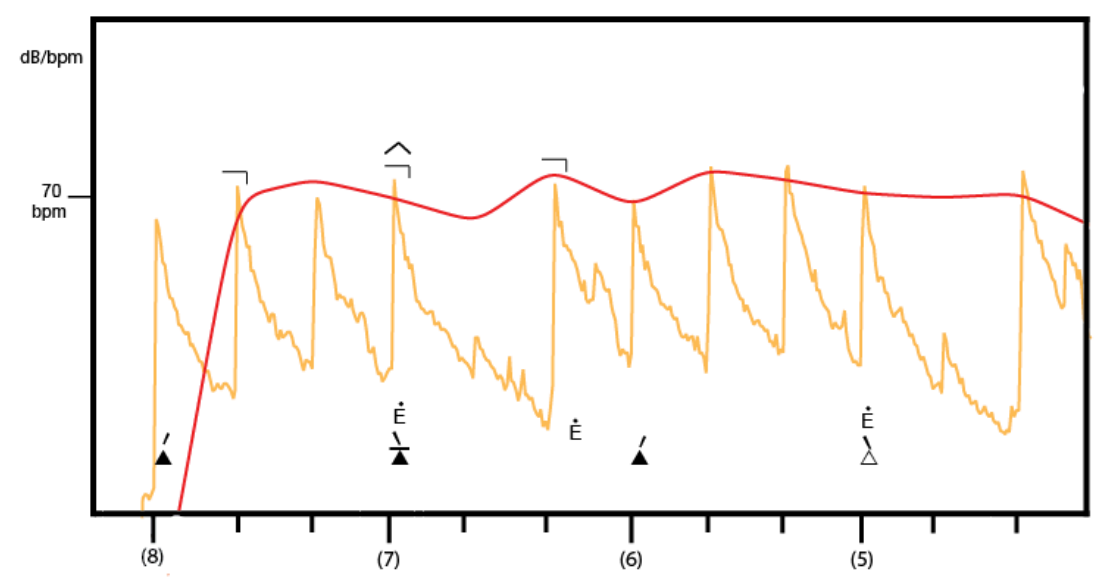

Figura 2: Exemplo dos gráficos que serão utilizados nas análises 


\begin{tabular}{|l|c|l|c|}
\hline \multicolumn{2}{|c|}{ ACENTOS } & \multicolumn{2}{c|}{ ACENTUAÇÕES } \\
\hline Métrico & Dinâmica & - \\
\hline $\begin{array}{l}\text { Rítmico } \\
\text { (ictus })\end{array}$ & & Agógica & \\
\hline Expressivo & $\bullet$ & & \\
\hline
\end{tabular}

Tabela 2: Simbologia utilizada nas análises

\section{Análise dos dados: acentuação e a técnica violonística em Adelita de Tárrega}

A escolha de Tárrega para iniciar nossa análise se deve primeiramente ao fato de ser contemporâneo a Lussy. Desse modo podemos inferir algumas concepções estilísticas comuns a compositores e performers da época. Além disso, Tárrega foi um importante performer e pedagogo do instrumento. Desse modo sua obra pode conter aspectos comuns ao pensamento de Lussy. Já na escolha da obra, Adelita, levamos em consideração sua curta duração e porque contém vários elementos conectados à teoria de Lussy, como exemplo, os acentos expressivos nos primeiros compassos.

Os performers escolhidos atendem aos critérios de performances de experts e diferenças geracionais, resultando que os escolhidos foram Andrés Segovia, em gravação de 1956, David Russel, de 1991 e Marcelo Kayath, de $1993 .{ }^{6}$

Incialmente iremos utilizar a visão analítica lussyana e tentar classificar os elementos expressivos das frases, ou frases-ritmos. ${ }^{7}$ No Exemplo 1, vemos a indicação dos acentos métricos na parte inferior que apontam para uma frase bastante normativa (quatro compassos) nos moldes tradicionais do arco frasal. Os acentos rítmicos (ictus inicial e final) indicam agrupamentos monopódicos ${ }^{8}$ na

\footnotetext{
${ }^{6}$ Vide Segóvia (1956), Russel (1991) e Kayath (1993).

${ }^{7} \mathrm{O}$ termo utilizado por Lussy para designar o que chamamos hoje de frase musical é rhytmé. A tradução inglesa de 1882 do tratado de Lussy utilizou o termo Phrase Rhythm (ritmo de frase). Posteriormente, William Rothstein (1989) também adota esse termo. A vantagem desse termo é que ele dá à frase musical a predominância de seu aspecto rítmico, e de acordo com os conceitos lussyanos, o ritmo é o aspecto mais importante para uma performance expressiva. Por isso adotamos a tradução de rhytmé como sendo frase-ritmo.

${ }^{8}$ Monopódicos e Dipódicos são termos utilizados por Lussy para indicar agrupamentos de um em um, e dois em dois compassos. Aparentemente isso tem relação com a análise poética.
} 
primeira semifrase e dipódico na semifrase subsequente obtendo a organização ritmo-frasal $8=4+4=(1+1+2)+(1+1+2)$. Mas o mais importante é a indicação dos acentos expressivos-métricos que ocorrem em cada segundo tempo dos compassos. A justificativa para esses acentos expressivos na teoria lussyana é a nota longa ocorrendo em tempo fraco que gera em nossa escuta um tipo de síncopa em conflito com a métrica. Já no quarto compasso, o acento expressivo é classificado pelo retardo da resolução da nota Mi5 por sua apojatura superior Fá5.

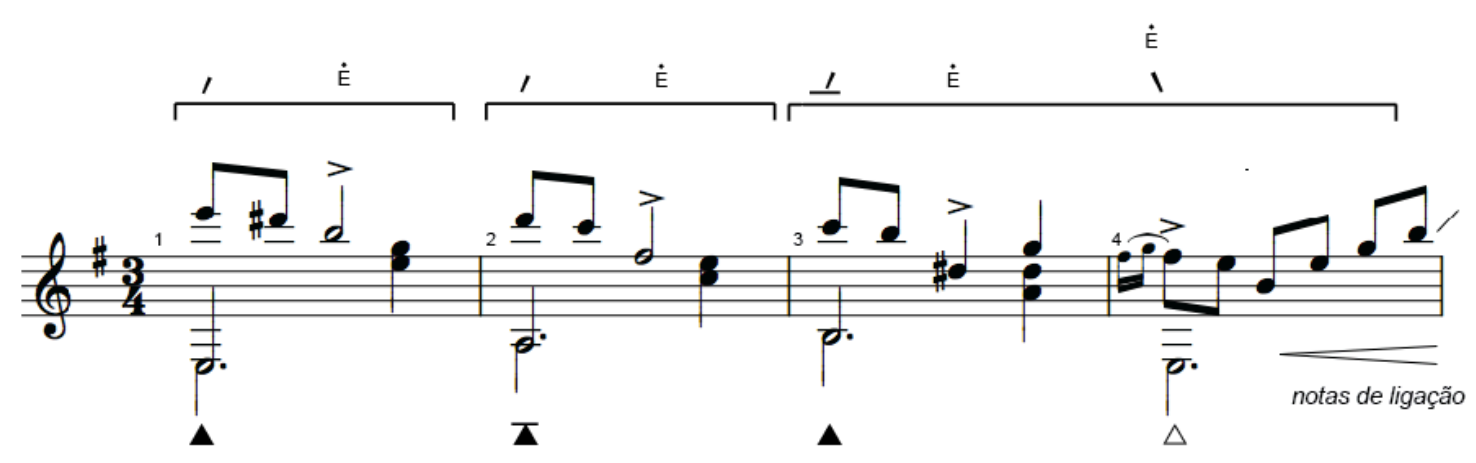

Exemplo 1: Análise dos elementos expressivos em Adelita de Tárrega, c. 1-4

Segundo a teoria lussyana os acentos expressivos são necessários porque a nota longa, que indica a tesis (repouso do motivo), luta contra a métrica. Desse modo a frase como um todo parece estar deslocada e fora de fase em relação à métrica. Na recomposição feita no Exemplo 2 observamos como a frase poderia ser escrita se estivesse em fase. As colcheias agem como se fossem anacruses e a nota longa volta para o tempo forte do compasso. Há duas maneiras de pensar as acentuações. A primeira é priorizando a continuidade do desenho motívico até o final de frase, acentuando todos as notas longas, incluindo a nota Si4 (Exemplo 2a). O resultado é que as notas longas formarão nos nossos ouvidos uma estrutura de dominante. A segunda opção é utilizar o princípio da atratividade melódica, em que o Ré\#5 (sensível) é atraído pela tônica Mi5. Nesse caso, o performer deve acentuar tanto o Ré» quanto o Mi. 


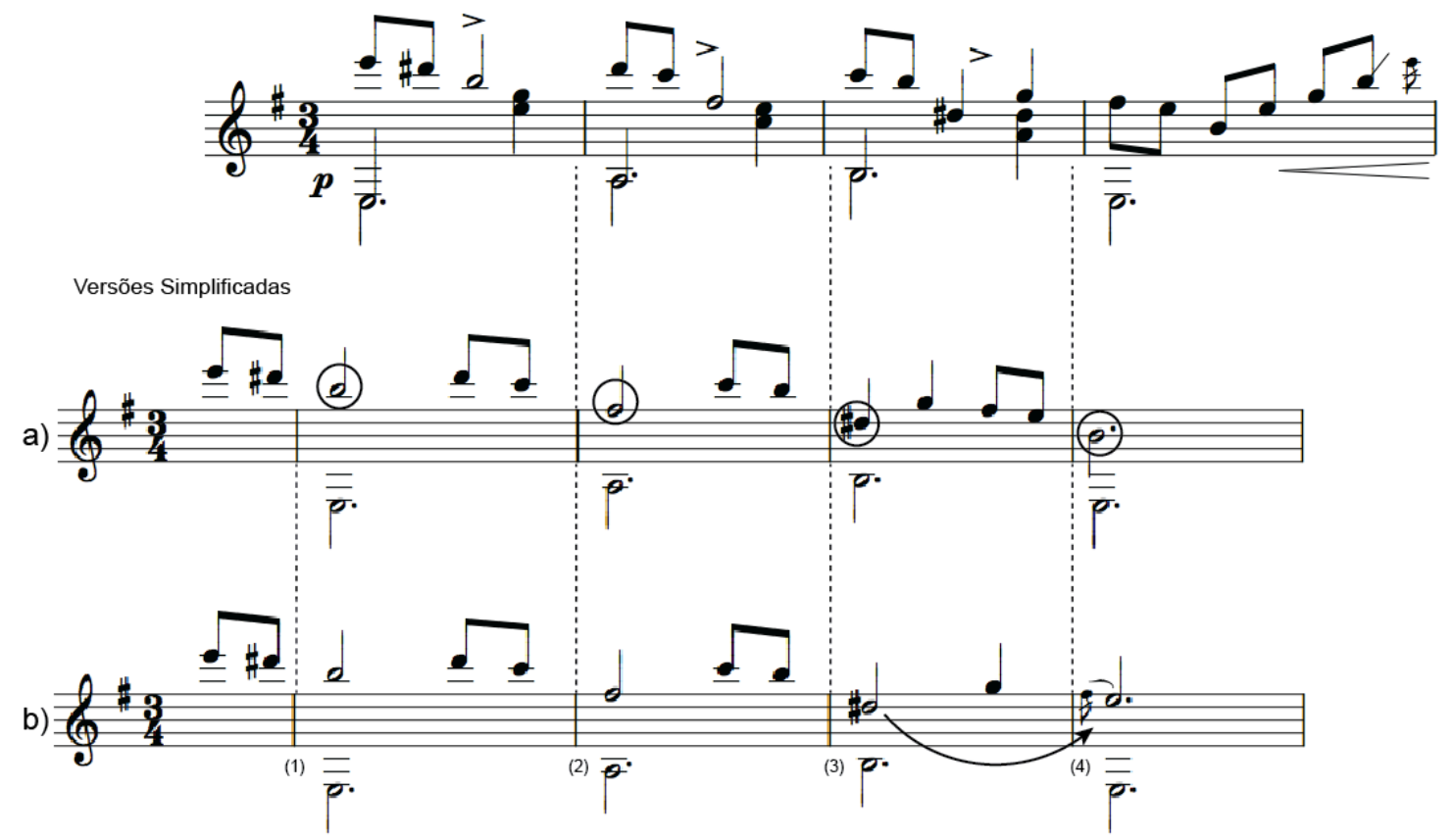

Exemplo 2: Recomposição dos primeiros compassos, recolocando a melodia em fase

$\mathrm{Na}$ Figura 3 temos os dados extraídos da performance da parte $\mathrm{A}$ executada por Segóvia onde estão expostos dois parâmetros: dinâmica e agógica. Os dados mostram que Segóvia acentua as notas longas que sempre acontecem no segundo pulso de cada compasso (pulsos 1.2, 2.2, 3.2). Observe os ataques feitos nas marcações métricas $(\boldsymbol{\Delta})$ e os indicados como acentos expressivos $(\dot{E})$, que deveriam soar "fraco" por sua posição, mas acabam ganhando proeminência sobre todos os outros pulsos.

Segóvia (vide Figura 3) opta pela interpretação dada no Exemplo 2a em que é acentuada dinamicamente a nota Fá5, que por sua vez é interpretada como acento expressivo e apojatura superior da nota Mi5 $(\triangle)$. Outra região em que ocorre a maior atividade dinâmica é nas notas de ligação (notes de soudure) que trazem ao ouvido a expectativa de um retorno à melodia. 


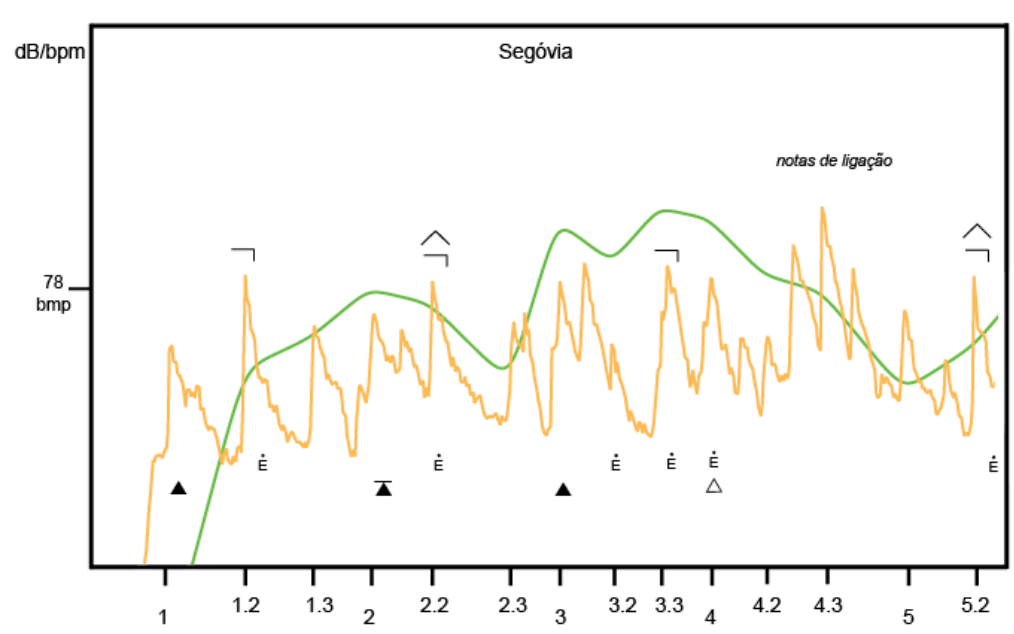

Figura 3: Performance de Andrés Segovia de Adelita, c. 1-4

Outro aspecto importante é que a acentuação nas notas expressivas feitas por Segóvia é uma soma das acentuações dinâmicas e agógicas. Observe que toda vez que há o pico dinâmico referente ao acento expressivo há também uma forte desaceleração dinâmica, reforçando a saliência da nota (vide Figura 3).

A partir da visualização do espectrograma da variação melódica (vide Figura 4) podemos detectar a utilização da técnica de apoios de mão direita visando o destaque da nota melódica. Ainda no espectrograma podemos ver o ataque da nota Fá\#5 com maior intensidade e mais corpo timbrístico, além da variação de frequência causada pelo intenso vibrato na sustentação da nota longa.

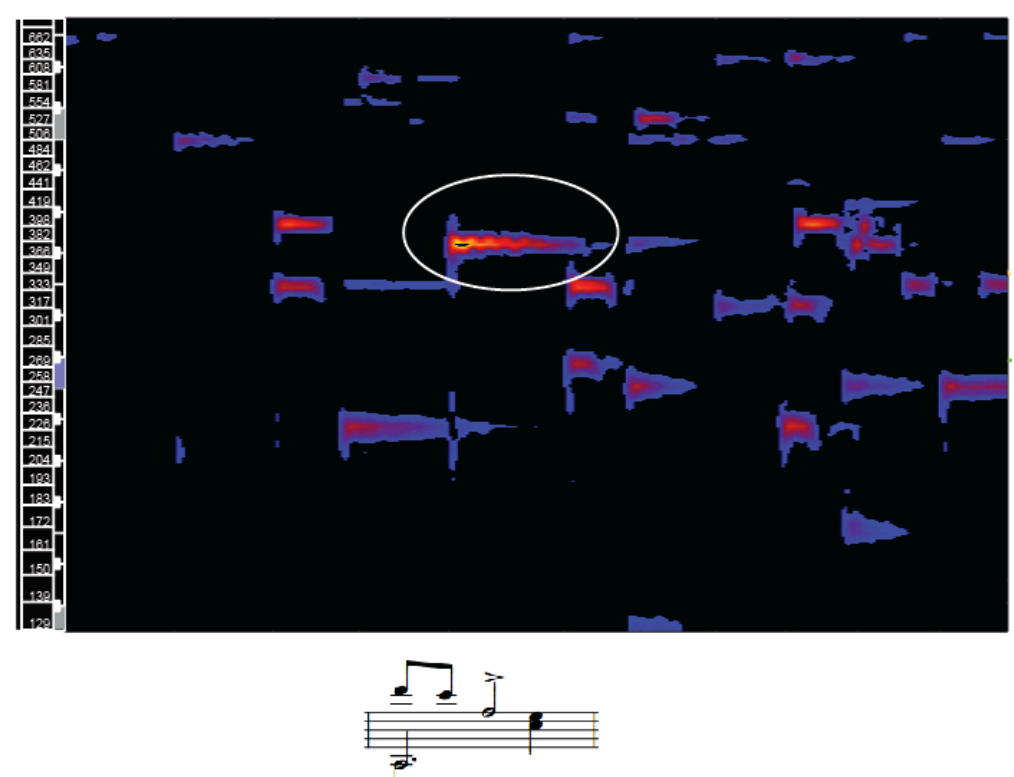

Figura 4: Utilização da técnica de apoio por Segóvia para acentuar a nota expressiva 
MUSICA THEORICA Revista da Associação Brasileira de Teoria e Análise Musical 2018, v. 3, n. 2, p. 227-257 - Journal of the Brazilian Society for Music Theory and Analysis@ TeMA 2018 - ISSN 2525-5541

Diferentemente de Segóvia, David Russel (vide Figura 5) parece dar mais importância aos acentos métricos. É possível ver que ele acentua dinamicamente as notas iniciais de cada compasso. Por outro lado, nos acentos expressivos, ele busca dar proeminência agógica. Russel parece alternar deliberadamente acentuação dinâmica para a métrica e acentuação agógica para o acento expressivo. Mas quando chega no trecho cadencial, ele parece somar os dois parâmetros para salientar a finalização da estrutura.

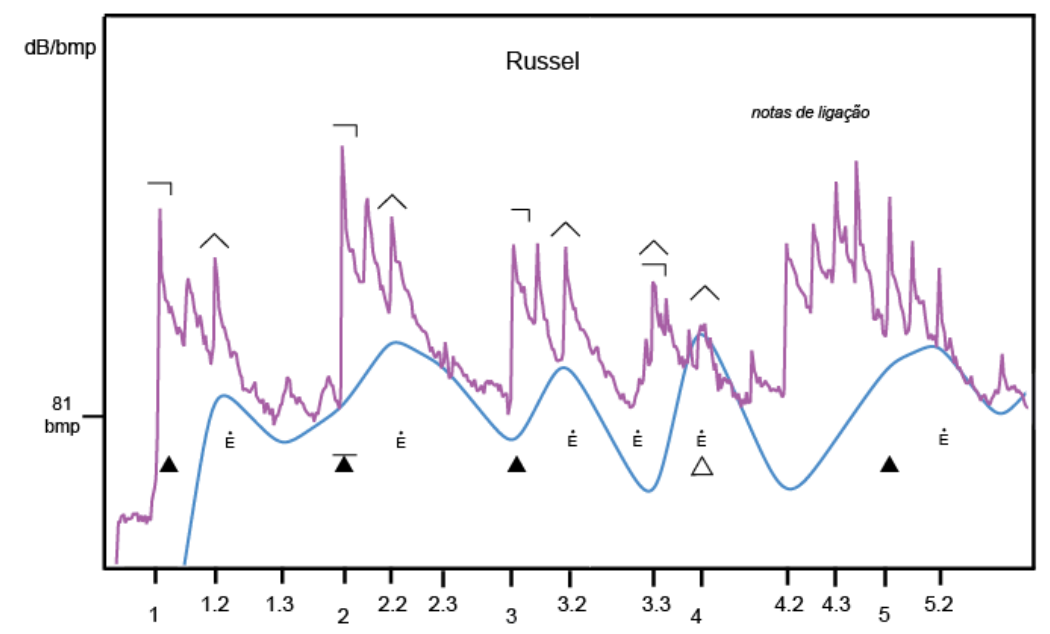

Figura 5: Performance de David Russel da peça Adelita, c.1-4

Essa alternância entre os dois tipos de acentuação e os visíveis cortes dinâmicos (pausas) resultam numa articulação muito similar aos agrupamentos monopódicos nos dois primeiros compassos e dipódicos nos dois finais. Também é possível verificar no segundo nível dinâmico a articulação da frase toda conforme o estilo arco. No trecho final, nas notas de ligação, é possível verificar a importância dada à nota Si4 no pulso 4.2 que soma as acentuações dinâmica e agógico aproximando-se de uma interpretação conforme o Exemplo 2a.

Os ataques veementes nos tempos fortes dos compassos podem ser confirmados pelo espectro dos primeiros compassos (vide Figura 6), ao passo que as notas longas posteriores recebem pouca saliência. Também é possível detectar o ataque maior na nota Ré6, compasso 2, que também pode ser interpretado como o pico do arco dinâmico feito por um apoio mais consistente. 


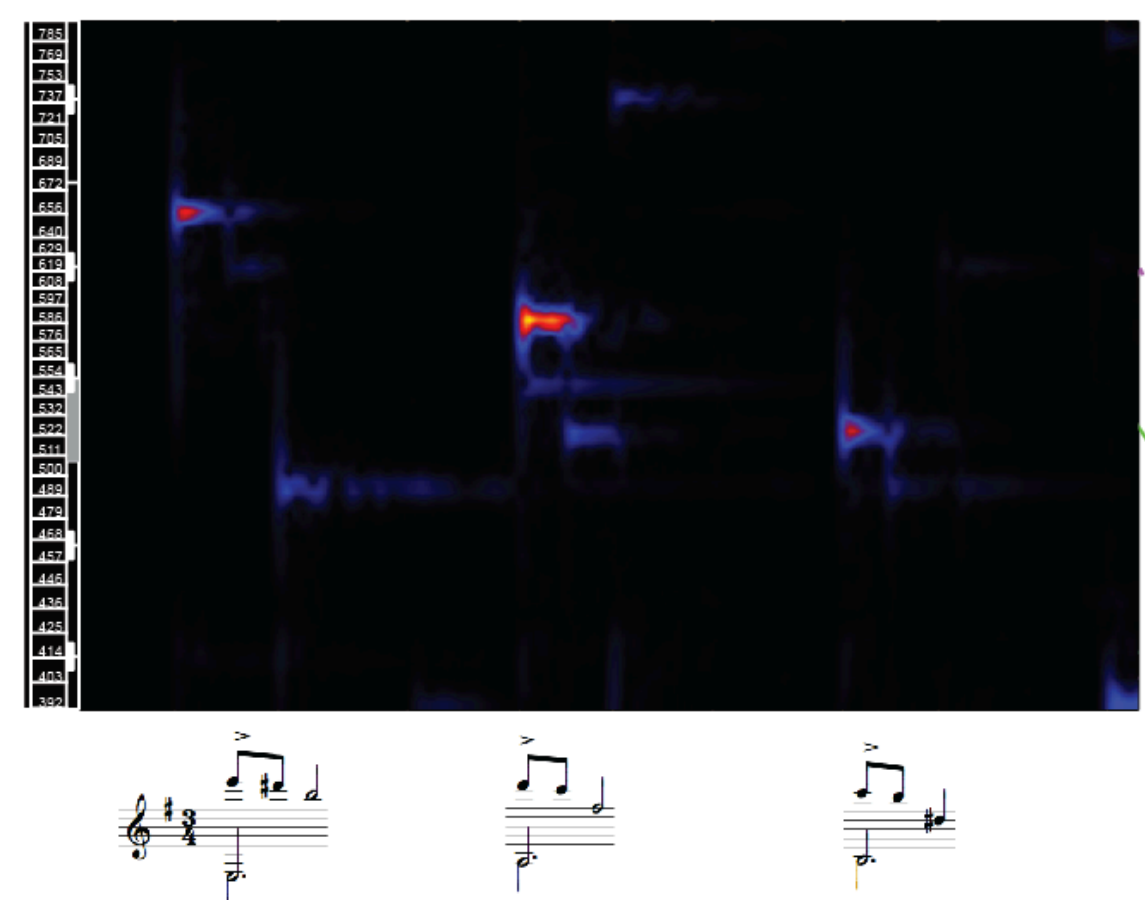

Figura 6: Espectrograma mostrando os ataques e apoios nos tempos fortes dos c. 1 a 3 de Adelita

Em uma terceira performance, realizada por Marcelo Kayath, observamos uma regularidade nas acentuações dinâmicas e uma maior rigidez temporal. A Figura 7 mostra que ele não diferencia acentos métricos e expressivos. Isso pode ser confirmado por não haver nenhuma acentuação dinâmico-agógica detectável nesse trecho.

Quando olhamos para a linha de variação temporal podemos dizer que a interpretação de Kayath busca uma maior regularidade, evitando qualquer tipo de tempo rubato. Apesar disso, há um único momento em que se percebe a variação agógica: nas notas de ligação visando demarcar o final da frase e início da próxima. É possível afirmar também que, enquanto Segóvia utiliza apoio nos acentos expressivos, e Russel utiliza nos acentos métricos, Kayath utiliza apoio tanto nos acentos métricos quanto expressivos, sem dar proeminência para algum deles (Figura 8). 
MUSICA THEORICA Revista da Associação Brasileira de Teoria e Análise Musical 2018, v. 3, n. 2, p. 227-257 - Journal of the Brazilian Society for Music Theory and Analysis @ TeMA 2018 - ISSN 2525-5541

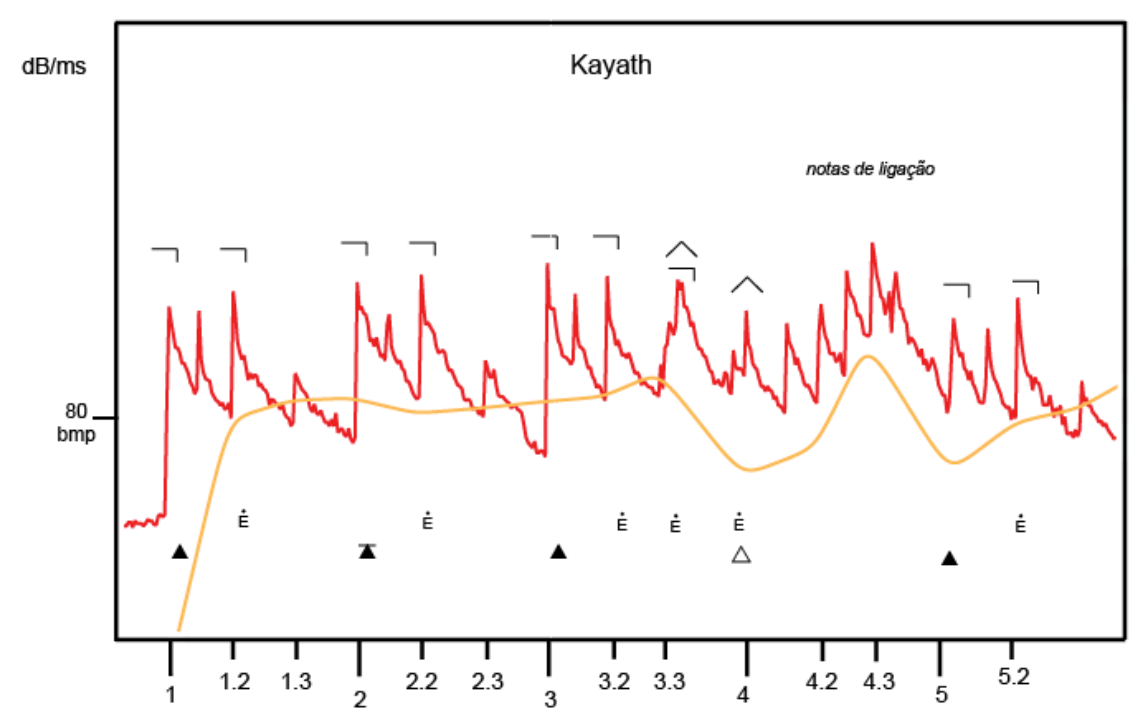

Figura 7: Dados da performance de Marcelo Kayath de Adelita de Tárrega, c. 1-4

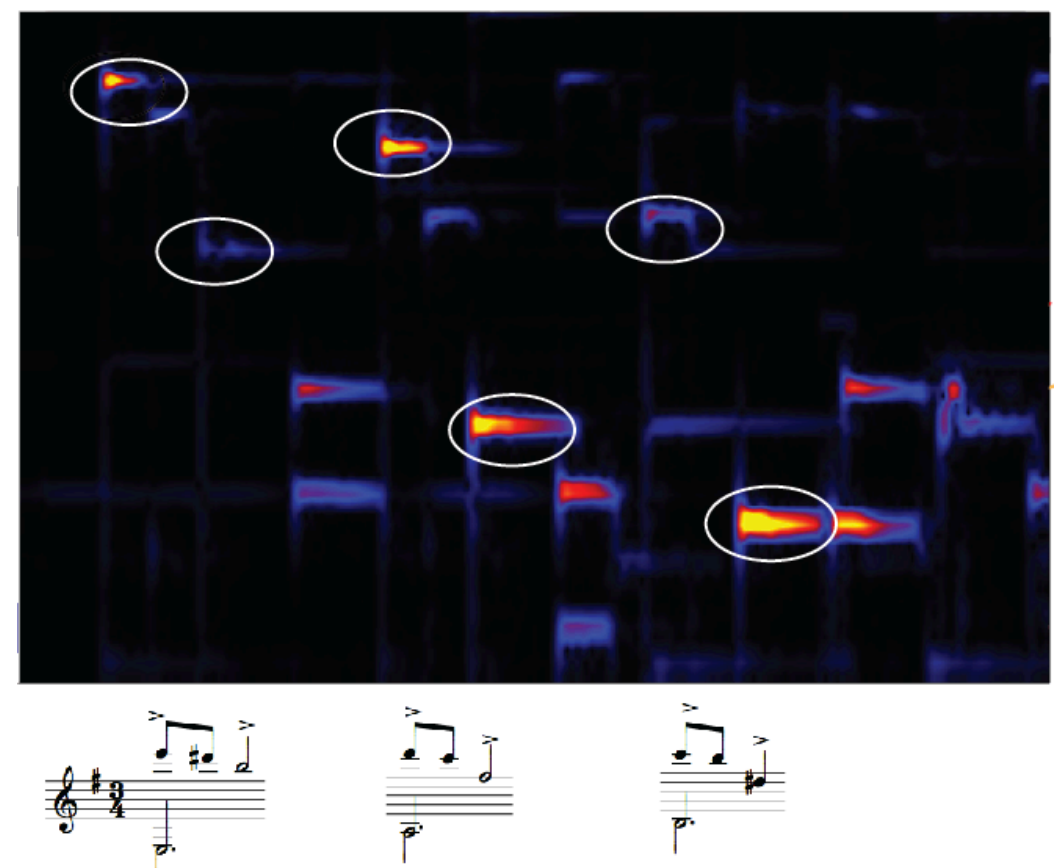

Figura 8: Espectrograma mostrando as acentuações dinâmicas com apoio de Kayath

Ampliando a análise para o agrupamento periódico, podemos observar o movimento a longo prazo e verificar como cada intérprete comunica as estruturas de suas interpretações. O Exemplo 3 configura os agrupamentos hierárquicos a níveis de motivo, semi-frase, frase e período. A parte mais importante nessa análise é como esses agrupamentos comunicam as estruturas frasais de antecedente-consequente. 

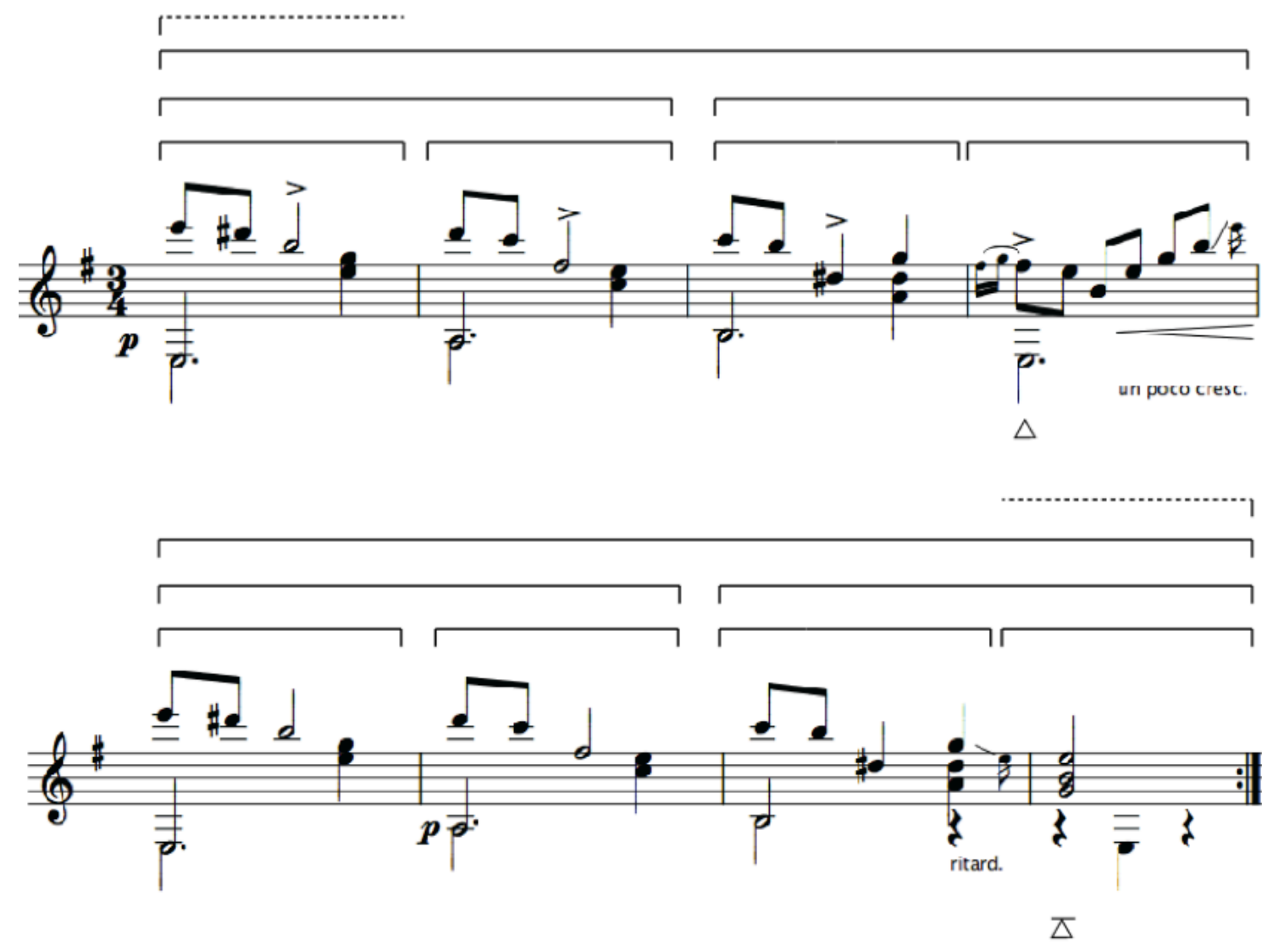

Exemplo 3: Hierarquia de agrupamentos no primeiro período (parte A) de Adelita, c. 18

Se compararmos as variações agógica e dinâmica das três gravações (Figura 9) observamos que a performance de Segóvia é bastante irregular, no sentido de não haver uma recorrência ou padrão de repetições. Ele procura ressaltar cada motivo e cada nota, assim como as pequenas estruturas. A única regularidade encontrada são os ritardandos nas situações cadencias. Russel parece bastante consciente de suas variações, pois há uma regularidade visível em cada compasso na alternância entre as acentuações. Já Kayath parece fazer uma performance linear, com poucas variações tanto dinâmicas quanto agógicas, destacando apenas estruturas maiores, como o final de cada frase ou período. 
MUSICA THEORICA Revista da Associação Brasileira de Teoria e Análise Musical 2018,

v. 3, n. 2, p. 227-257 - Journal of the Brazilian Society for Music Theory and Analysis @ TeMA 2018 - ISSN 2525-5541
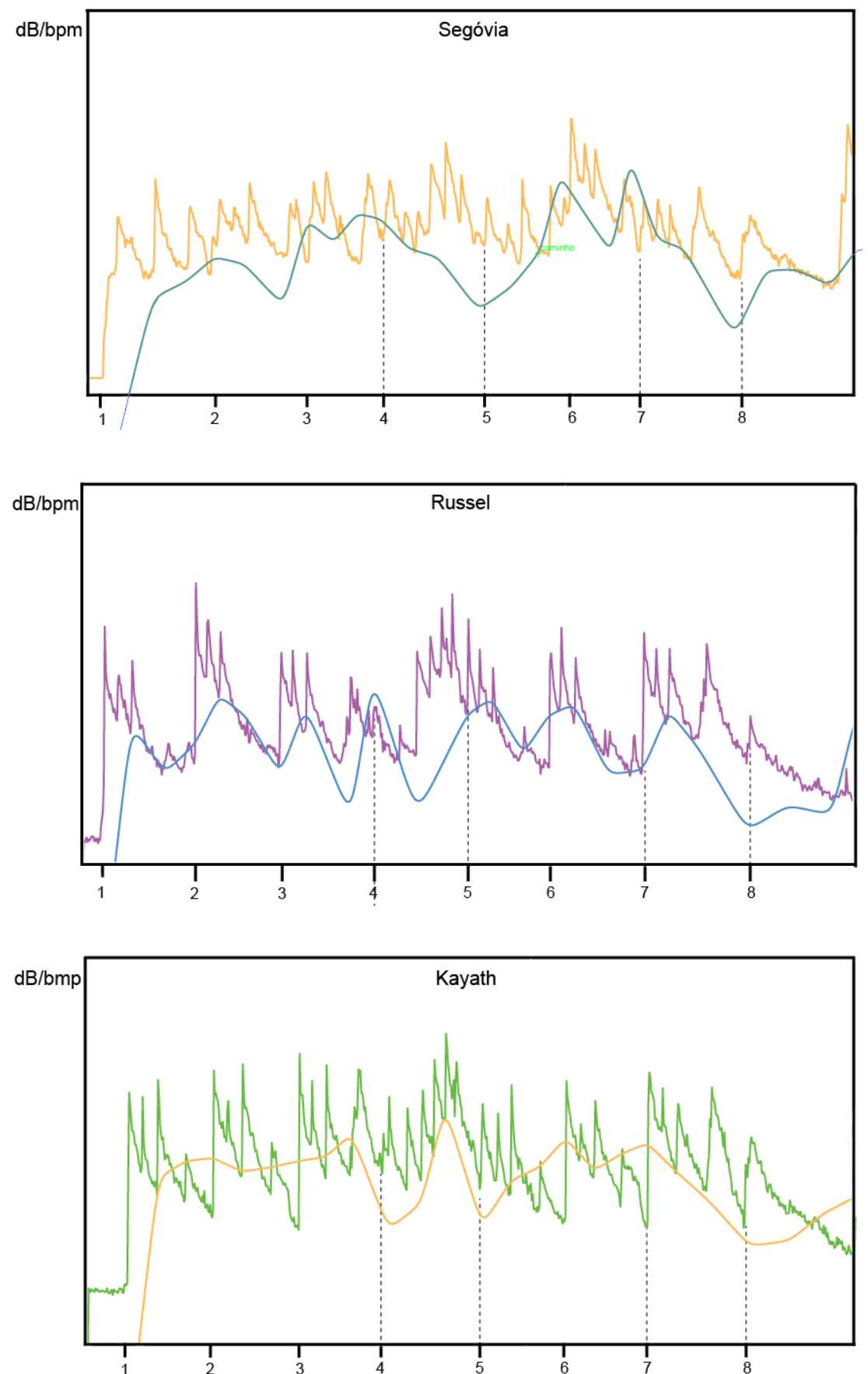

Figura 9: Diferenças nas três performances no âmbito do período

Ainda sobre os aspectos cadenciais, em especial nas notas de ligação dos compassos 4 e 5, observamos que Russel e Kayath fazem um crescendo conjuntamente com um acelerando, conjugando os dois parâmetros. Segóvia, de maneira oposta, faz o crescendo aliado a um ralentando. Nesse caso podemos fazer alguma correlação estilística entre Segóvia, que herda uma tradição do século XIX e dos outros violonistas já no contexto do século $X X$, que seguem 
novas concepções. Segóvia parece incorporar a ideia (metafórica) lussyana de que o gesto está em direção ascendente e representa um tipo de obstáculo. Se há um obstáculo, a tendência é desacelerar devido à fadiga e à força da gravidade (Silva 2018). Observe que, de maneira geral, os indicadores vão em sentidos contrários em vários momentos na performance de Segóvia, enquanto que nas de Russel e Kayath, a dinâmica e a agógica parecem bem vinculadas uma à outra.

Uma regularidade que observamos é que todas as ocorrências de acordes de dominante, reconhecidos como acento expressivo, foram executadas em forma de arpejo. Na Figura 10, vemos a conversão dos onsets na imagem obtida pelo espectrograma. Observe-se as indicações da linha pontilhada branca que demonstra a simultaneidade, ou não, das notas. Segóvia e Kaytah fazem amplo arpejo tanto na dominante quanto na tônica para fechar o período. Já Russel faz arpejo apenas na dominante resolvendo a tônica em ataque plaqué.
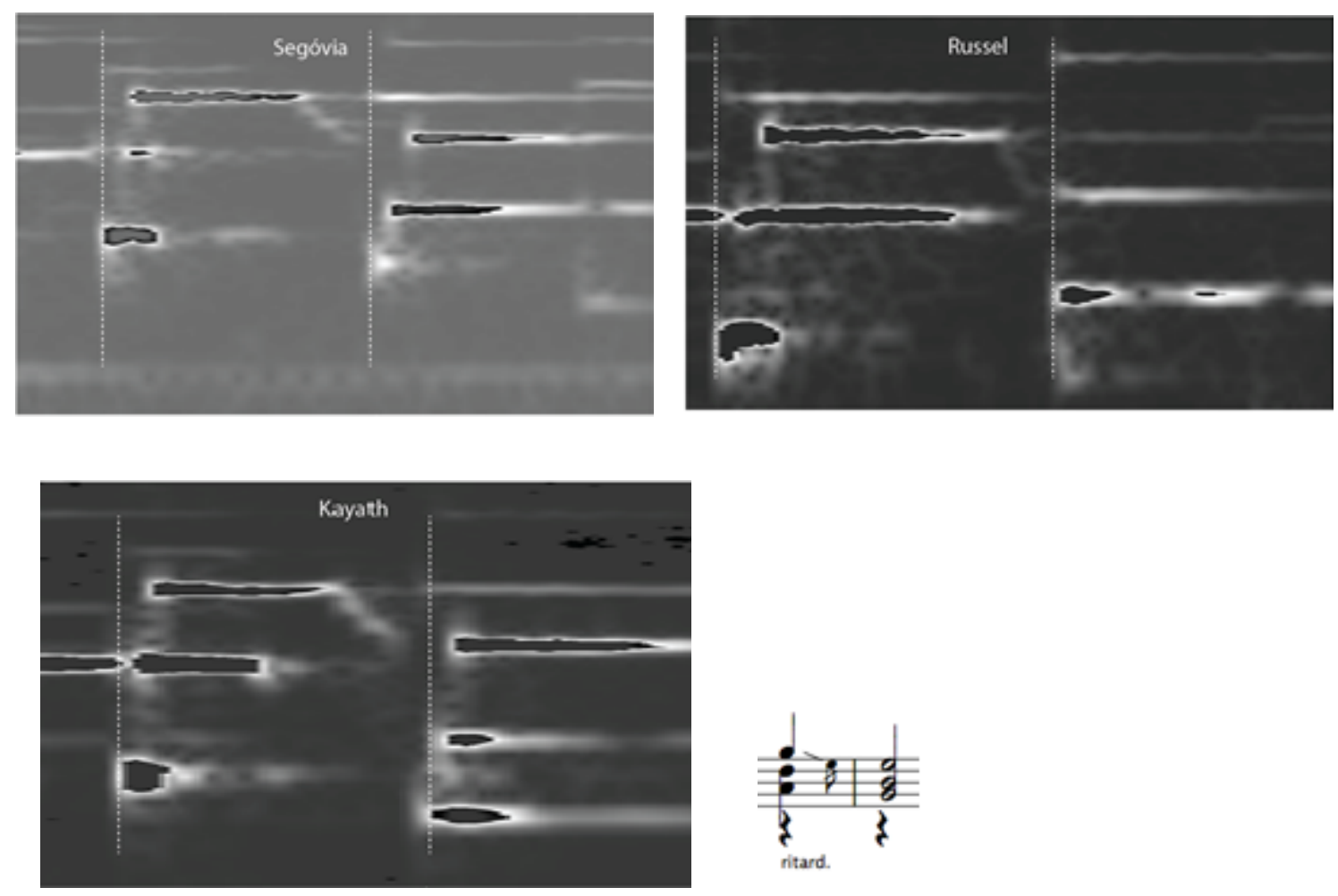

Figura 10: Espectrograma contendo os onsets dos acordes cadencias

Se utilizarmos o mesmo raciocínio indutivo lussyano, poderíamos cogitar que essa amostra representa uma característica geral do universo violonístico: a tendência dos performers de tocar os acordes de dominantes em finais de frase utilizando a técnica de arpejo. Obviamente, por enquanto essa é apenas uma 
MUSICA THEORICA Revista da Associação Brasileira de Teoria e Análise Musical 2018, v. 3, n. 2, p. 227-257 - Journal of the Brazilian Society for Music Theory and Analysis @ TeMA 2018 - ISSN 2525-5541

indicação que precisa ser comprovada com mais obras e mais performers para se validar como uma generalização dentro da gramática tonal violonística. Embora não seja o objetivo dessa análise, podemos afirmar que o acorde arpejado também é uma forma de acentuação? E talvez seja uma manifestação diferente da acentuação agógica por fazer um retardo temporal? É provável que sim, pois em todas as ocasiões em que há arpejos, os softwares apontaram significativa variação agógica.
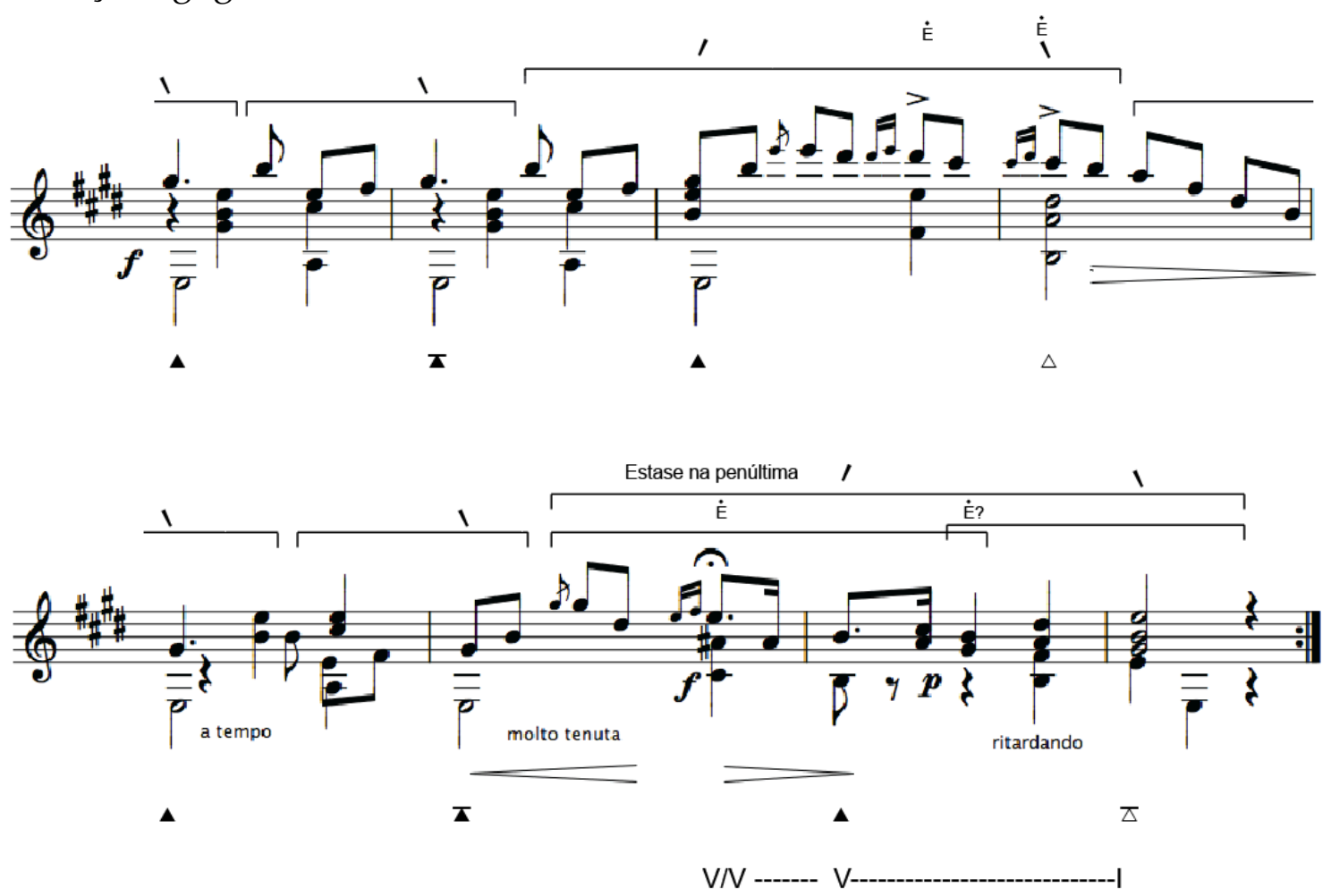

Exemplo 4: Análise dos elementos expressivos da parte B de Adelita, c. 9-16

Prosseguindo a análise na parte B da obra observamos, no Exemplo 4, agrupamentos similares aos da parte A: dois ritmo-frases monopódicos e um dipódico resultando na forma $8=4+4=(1+1+2)+(1+1+2)$. Há poucos conflitos métricos, como os que ocorreram na parte anterior, no entanto os acentos expressivos encontrados são acentos expressivo-rítmicos ocorrendo na forma de retardos das resoluções dos acordes (c. 11-12). Há também um acento expressivoharmônico no compasso 6 causado pela dominante da dominante, que é marcado pelo compositor através da fermata. Esse mesmo acorde adquire uma grande importância no aspecto global da obra, pois é entendido como uma "estase na penúltima", com a função de criar forte expectativa para a resolução posterior. 
A organização da obra parte do conceito dualista e conflitante entre as partes A e B. O elemento mais visível é o perfil tonal que constrói um conflito entre as tonalidades homônimas, Mi menor e Mi maior. Outro fator menos perceptível à primeira vista é o conflito rítmico-métrico presente entre as partes. Como observado no início da análise, na parte A ocorre um tipo de agrupamento rítmico em defasagem com a métrica. O performer deveria então acentuar a nota longa para destacar essa nota expressiva. Por outro lado, a base rítmica da parte B é o oposto da anterior (vide Exemplo 5). É como se a melodia tivesse entrado em fase com a métrica, criando uma estrutura mais regular através da nota longa que ocorre na parte estável do compasso.
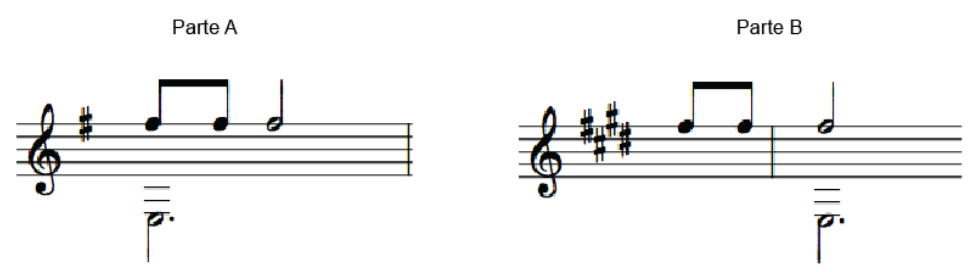

Exemplo 5: Agrupamentos motívicos (unidades-compasso) nas partes A e B de Adelita

O fraseado de Segóvia é similar à nossa análise com base em Lussy (Exemplo 4). Na linha agógica, mostrada na Figura 11, aparecem pequenos acelerandos em direção ao tempo forte dos compassos. Esses acelerandos reforçam o sentido de unidade do motivo e de expressão do sentido da anacruz. As frases têm sempre sentido anacrústico para enfatizar a chegada no downbeat. Isso vai de encontro à afirmação de Sloboda (2008), baseada na psicologia da Gestalt, de que nossa percepção tende a agrupar elementos pela lei da proximidade. Esses elementos tendem a ser percebidos como uma única unidade, separada de outros elementos mais distantes. Nesse sentido, os acelerando desempenham um papel unificador por aproximar elementos estruturais da ritmo-frase e apresentá-los aos ouvintes com uma só unidade.

Também é possível notar que Segóvia alterna entre acentuação dinâmica e agógica. A acentuação dinâmica é sempre feita no último tempo do compasso (arsis) enquanto que a resolução (tesis) é feita com o acento agógico criando uma dinâmica descendente no âmbito do motivo. Nas notas marcadas com acento expressivo-rítmico, Segóvia busca ressaltá-los através da acentuação dinâmica, assim como ele inicia o emprego de apoio nas notas de ligação (N.L.). O espectrograma da Figura 11 demonstra essas escolhas interpretativas de Segóvia ao ressaltar a continuidade melódica que inicia nas N.L. e se aloca na voz 
MUSICA THEORICA Revista da Associação Brasileira de Teoria e Análise Musical 2018, v. 3, n. 2, p. 227-257 - Journal of the Brazilian Society for Music Theory and Analysis @ TeMA 2018 - ISSN 2525-5541

intermediária da frase. O espectro, por outro lado, mostra a utilização da técnica de apoio, usada para que a melodia na voz intermediária seja destacada.

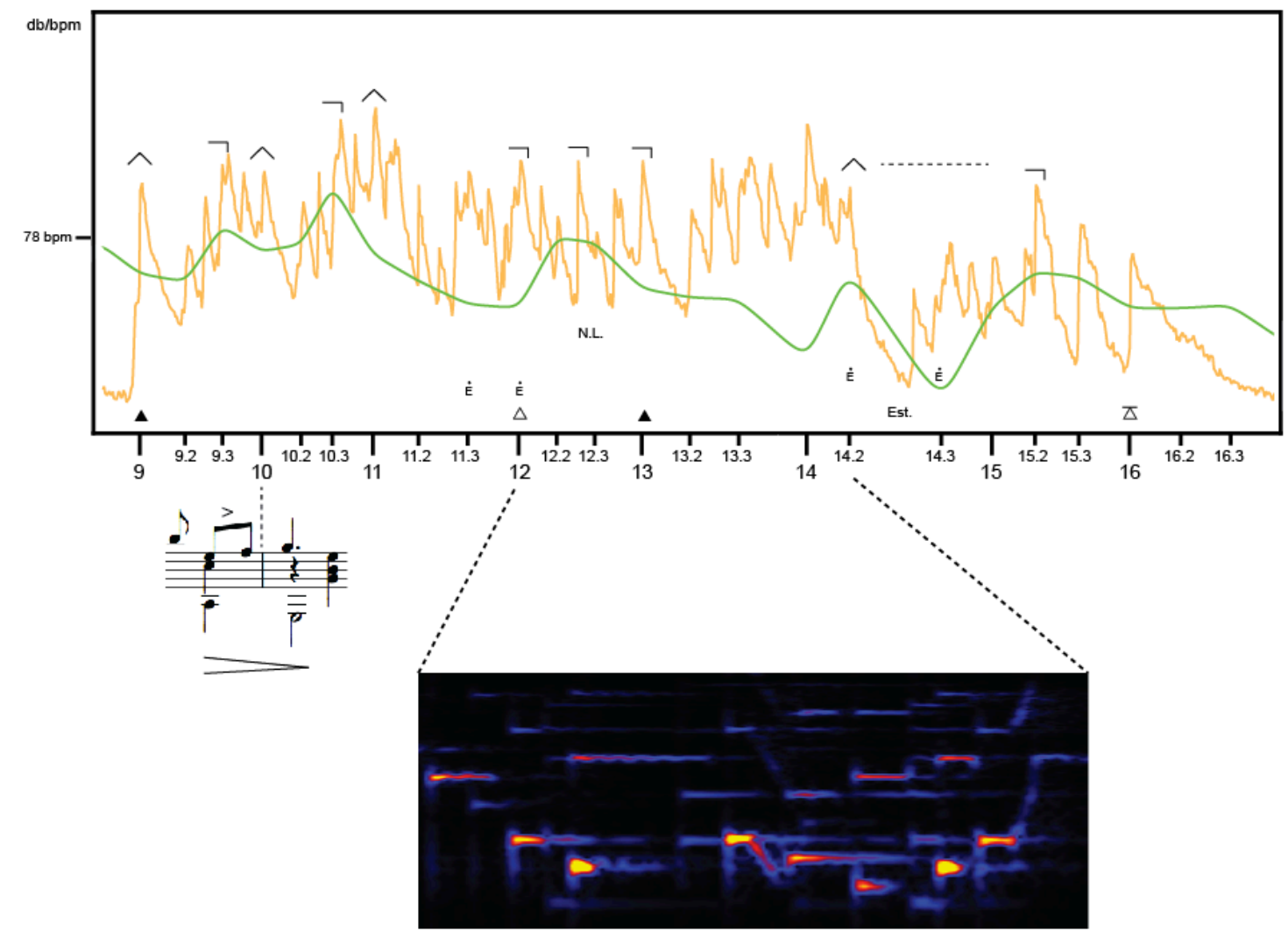

Figura 11: Performance de Andrés Segóvia, da parte de B de Adelita, c. 9-16

Segóvia faz uma forte acentuação agógica na nota que classificamos como acento expressivo-melódico (c. 14.2). No entanto, no c. 14.3, ele contraria a marcação do compositor evitando a fermata indicada na partitura. Tárrega escreveu essa fermata num acorde de Lá\# diminuto por se tratar de acento expressivo-harmônico que se torna uma estase na penúltima (Est.). Há necessidade de salientar esse acorde pois ele representa uma desestabilização da tonalidade de Mi maior, por se tratar da $4^{\mathrm{a}}$ aumentada da tonalidade. Nesse sentido é o ápice do tema, mas Segóvia ignora o destaque proposto por Tárrega e faz um acelerando que nos conduz à cadência final. No entanto, Segóvia reconhece o último acento expressivo (c. 15.2) causado pela elisão de dois motivos, que ele salienta com uma acentuação dinâmica.

A performance de David Russel, analisada na Figura 12, também articula as frases de acordo com nosso esquema do Exemplo 4. Entre os pulsos 9.2 e 10 (assim como no 10.2 e 11) é possível identificar o acelerando em direção ao acento métrico, trazendo unificação ao motivo, processo similar ao ocorrido na gravação 
de Segóvia. No entanto, há diferenças substanciais na condução dinâmica. Russel opta por executar o motivo com um crescendo, acentuando o ictus final. Além disso, dá ampla ênfase ao trecho, através da soma das acentuações dinâmica e agógica, entendendo que essa passagem requer peso pois é a soma do ictus com o acento métrico. A acentuação é reforçada pela utilização da técnica de apoio, conforme constatamos na imagem da Figura 12, em que há uma ampla atividade nas notas que recaem no ictus/acento métrico. Ao executar esses motivos em crescendo e com acentuação no final, Russel opta por conferir a essa passagem o sentido de expressão de um movimento progressivo.

Na segunda frase do período, Russel parece reconhecer os três acentos expressivos detectados. O primeiro acento expressivo-melódico (c.14.2) é salientado por meio de uma ampla acentuação agógica. $\mathrm{O}$ acento expressivoharmônico (c.14.3), que é marcado com fermata por Tárrega, é enfatizado por Russel com uma dupla acentuação dinâmico-agógica. No último acento expressivo-rítmico, causado pela sobreposição estrutural (15.2, Russel utiliza uma acentuação dinâmica.

A performance de Marcelo Kayath, estudada na Figura 13, parece concordar com o fraseado de Segovia e Russel, fazendo pequenos acelerandos em direção ao ictus final somados ao acento métrico. No entanto, há discordância na condução dinâmica. Kayath parece dar prioridade ao ritmo do baixo acentuando o último e o primeiro pulso. Também é notado que ele prefere a acentuação dinâmica ao invés da agógica, tornando a performance mais metronômica.

$\mathrm{Na}$ primeira frase, Kayath também reconhece os acentos expressivorítmicos causados pelos retardos, dando a eles acentuação dinâmica (11.3) e agógica (12). Em seguida, nas notas de ligação (N.L.), Kayath realiza um amplo acelerando e chega ao ápice com uma acentuação dinâmica feita com a técnica de apoio. No compasso 14, Kayath procede de maneira similar a Russel, fazendo acentuação agógica tanto no acento expressivo-melódico quanto no expressivorítmico. 
MUSICA THEORICA Revista da Associação Brasileira de Teoria e Análise Musical 2018, v. 3, n. 2, p. 227-257 - Journal of the Brazilian Society for Music Theory and Analysis@ TeMA 2018 - ISSN 2525-5541

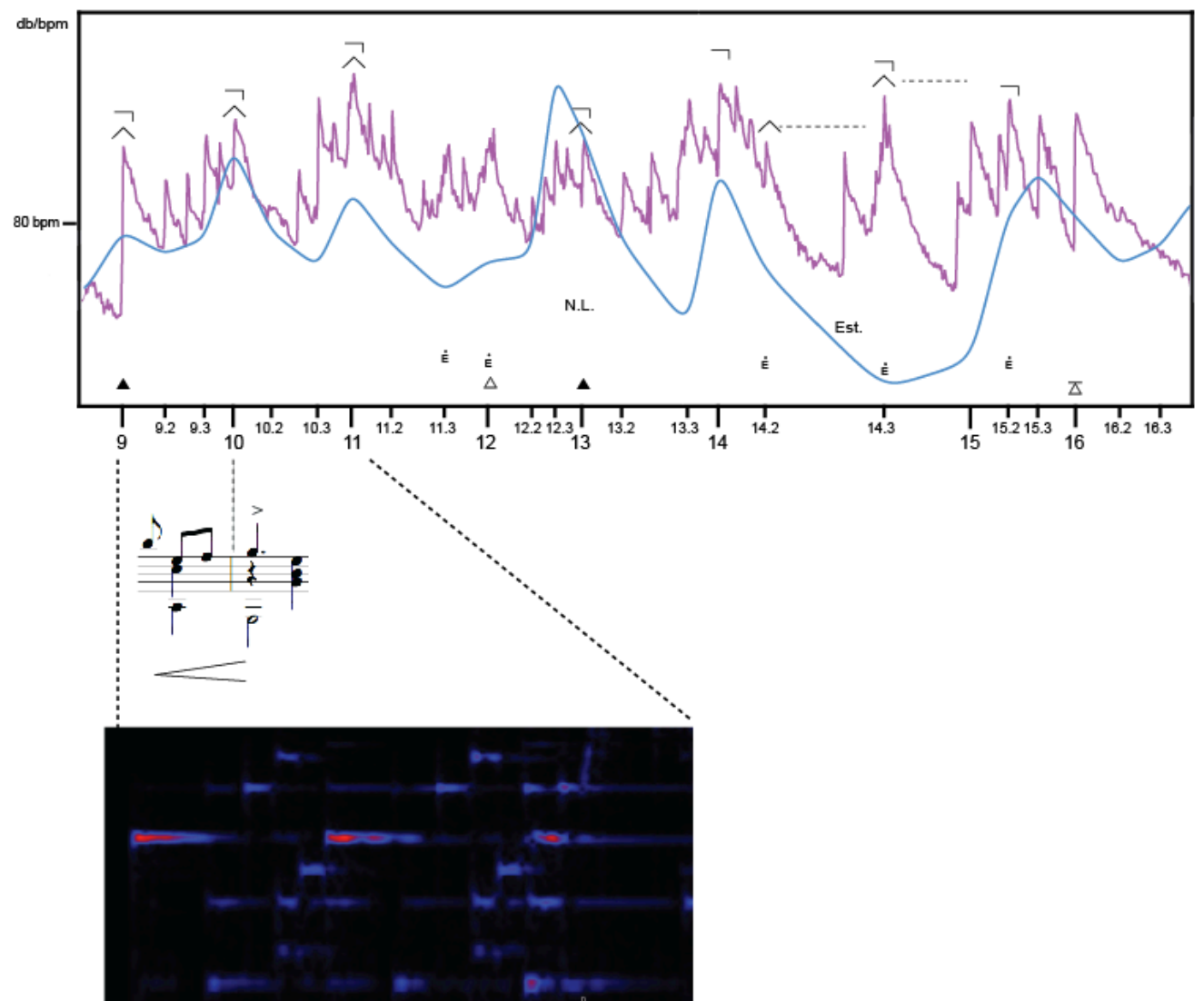

Figura 12: Performance de David Russel da parte B de Adelita, c. 9-16

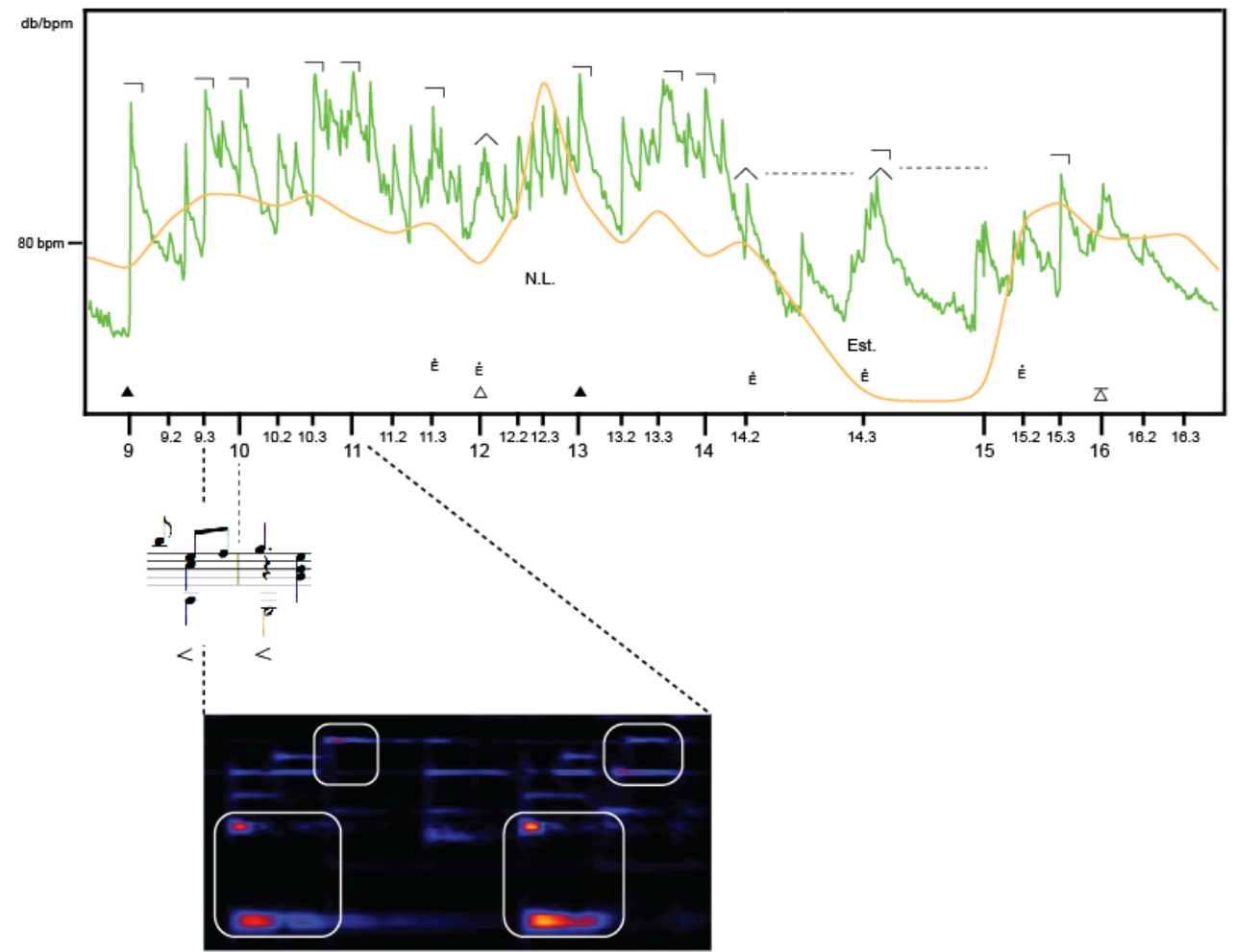

Figura 13: Performance de Marcelo Kayath da parte B de Adelita, c. 9-16 
Comparando as três análises, é interessante perceber as mudanças na concepção performática desde a tradição novecentista de Segóvia (que se aproxima das ideias de Lussy), até os performers do século XX. O Traité de Lussy adere a concepções de performance instrumental que têm como referência a imitação do canto, ou seja, as frases-rítmicas são realizadas a curto prazo, com delimitações mais constantes e fragmentadas imitando o processo de respiração de um cantor. Isso explica porque o tratado de Lussy evita falar em unidades hipermétricas com maiores detalhes, pois o importante é a comunicação do que seria musicalmente equivalente às palavras (motivos) de maneira legível, uma vez que as palavras são as unidades significantes mais importantes para o cantor.

Nota-se que grande parte dos processos de articulação dinâmica e agógica de Segóvia buscam ressaltar pequenas estruturas, dar ênfase a cada nota considerada importante, a exemplo do Fá\# (c. 2) onde ele realizou o acento dinâmico-agógico aliado ao extenso vibrato, típico do canto. Nenhuma outra nota do trecho recebe tanta evidência.

Até mesmo Schenker, ao falar da performance, evita utilizar seus tradicionais conceitos reducionistas. No domínio da performance, ele prioriza o nível superficial da obra (foreground). De fato, ele também concorda com Lussy sobre a performance como imitação do canto. Em seu projeto inacabado denominado 'Die Kunst des Vortrag' (A arte da performance) ele diz:

Se escrita para órgão, piano ou violino, música é sobre tudo "música" (quando ela é boa) e todas as peculiaridades instrumentais são, através de suas características comuns, muito mais unificadas do que separadas por variações em suas construções. E nós devemos buscar um instrumento ideal que de certo modo subjaz todos os reais, quero dizer, a voz humana, a qual, como a ferramenta artística mais natural, preenche todas as diminuições e prolongações de condução de vozes com sua alma, com as leis de sua performance, portanto ela é desenvolvida em qualquer instrumento que for aplicada (Schenker 2000, p. xiii).

As concepções de Schenker sobre performance postulam que o piano deveria conduzir sua expressividade através do que chamou de piano cantado (klaviersingen). Praticamente todos os seus exemplos são aplicações na superfície sonora de maneira muito similar a uma teoria dos acentos. Pablo Casals, que também herda essa tradição, diz que "cada nota deve cantar" (Casals apud Blum 1980, p. 2). Nesse contexto a variabilidade de cada nota no ato da performance é uma regra. Cada nota deve trazer sua própria característica desempenhando um 
MUSICA THEORICA Revista da Associação Brasileira de Teoria e Análise Musical 2018, v. 3, n. 2, p. 227-257 - Journal of the Brazilian Society for Music Theory and Analysis@ TeMA 2018 - ISSN 2525-5541

papel que lhe é único na trama sonora. Casals diz ainda que "variedade, é a grande palavra - na música como em tudo: variedade é uma lei da natureza" (Casals apud Blum 1980, p. 18). Como Casalas afirma que a saliência (acento) só se dá para as notas consideradas importantes, não estará ele se referindo exatamente aos acentos expressivos de Lussy? Ele diz que a formulação do sentimento interpretativo da música "emana de uma única fonte e fluindo em conjunto numa simples corrente. Notas que estão fora dessa corrente são frias sem significado" (Casals apud Blum 1980, p. 4).

Por outro lado, performers do século XX, como Alfred Brendel, buscam outros critérios para a construção de suas interpretações. Em uma conversa com o pianista, musicólogo e pedagogo austríaco Konrad Wolff (Brendel 1990, p. 225), Wolff afirma que grande parte da crítica considera Brendel o maior intérprete do repertório tradicional depois da era Schnabel (1882-1951). Mas Brendel busca evidenciar que eles têm concepções bem diferentes, quando diz:

Para mim, Schnabel interpreta muitas vezes comparando-a [música] com a 'linguagem', ou seja, com muitas paradas, pontuações, etc [...] Música não possui uma simples organização como essa. Até mesmo quando ela possui uma qualidade eloquente - uma qualidade de falante - ela não tem sentenças, pontos, ou organizações de palavras em ritmo de uma maneira que poderia ser facilmente uma comparação com a linguagem (Brendel 1990, p. 230).

Brendel evidencia um rompimento com a teoria dos acentos, ligada à poética, e diz que ter o canto como parâmetro para a execução instrumental não é aceitável porque o cantor limita seu fraseado ao seu aparato biológico (respiração), que por sua vez gera frases mais curtas e fragmentadas. A música instrumental, no contexto do piano, não precisa ser guiada pelo canto, e afirma que "você tem começo melódico e final melódico, mas também tem um começo harmônico e um final harmônico [...] e é mais importante conectar frases que separá-las" (Brendel 1990, p. 231). Ele explicita assim uma importante característica dos performers do século XX: o afastamento do bel canto e a maior valorização dos objetivos harmônicos. A harmonia determina formas a longo prazo e em geral podem gerar diferentes maneiras de abordar o material musical.

Essas informações reforçam que, de maneira geral, a performance herdada do século XIX tem o canto como referência interpretativa. De acordo com os gráficos da performance de Segovia observamos uma maior variabilidade principalmente na questão temporal, o que demonstra sua maior preocupação 
em comunicar as estrutura e notas mais singulares que representariam as palavras no discurso sonoro. Nesse caso, a teoria dos acentos faz mais sentido quando comparada às gravações como a do violonista espanhol. Já os instrumentistas do século XX parecem almejar a uma precisão rítmica mais apurada, uma maior continuidade e menor variabilidade entre repetições, com é caso do Kayath. Ou buscam também comunicar estruturas hipermétricas levando em conta os aspectos harmônico-formais, como é o caso de Russel.

\section{Considerações Finais}

Mathis Lussy foi um importante pedagogo da música no final do século XIX que também esteve conectado com o surgimento da musicologia moderna através de seus escritos sobre ritmo e performance (Lussy 1883, 1885). Seus tratados foram amplamente difundidos em conservatórios europeus, suprindo a demanda por materiais didáticos para a educação instrumental.

Verificamos que, embora Lussy tenha publicado trabalhos sobre história e didática pianística, as suas principais contribuições se concentraram no Traité de l'expression musicale (1874). Essa obra é pioneira no que tange a relação entre pensamento analítico e performático, e propõe uma mudança no conceito de expressão, deslocando-o da teoria das emoções para a teoria da análiseperformance, isto é, da expressão da alma para expressão da razão. Com isso, defendeu uma maior objetividade, abrindo espaço para uma discussão dos aspectos teórico, estrutural, psicológicos e comunicacional na performance.

A partir de uma leitura atual de Lussy observamos que ele fez uma diferenciação entre expressão (estética) e expressividade (performance) abrindo caminho para uma teoria expressiva na performance. Seu trabalho foi pioneiro no que se refere a teoria da expressividade, denominada neste caso como "teoria dos acentos aplicada" (Caplin 2008). Mas sua grande contribuição foi a construção da primeira abordagem empírica (qualitativa) da performance. Para isso, ele recorreu a experiências de escuta que envolveram edições de partituras e escuta de concertos de intérpretes renomados.

A construção de uma teoria expressiva lussyana consiste em duas etapas: análise dos acentos e prática das acentuações. A análise concentra-se nos acentos métrico, rítmico (ictus) e expressivo (patética) e aplicação na prática instrumental concentra-se nas acentuações agógica e dinâmica. Com isso, ele propõe uma 
comunicação expressiva das estruturas sonoras a partir da interconexão entre análise e performance.

Verificamos que seus objetivos, metodologia e a escolha de performance como fonte de dados nos remetem às abordagens da musicologia empírica. Nesse caso, propusemos a análise de uma obra para violão como experimentação, ou replicação das propostas de Lussy.

Aplicamos o modelo analítico lussyano na obra Adelita de Francisco Tárrega e buscamos corroborar a teoria com evidências da análise de três gravações da peça. Criamos também uma simbologia para os acentos e acentuações, e incluímos gráficos com os dados sobre dinâmica e agógica.

A dinâmica e agógica funcionam como demarcações auditivas entre o performer e o público que reconhecem tais nuances como coordenadas auditivas. O que elas indicam são os inícios e fins de estruturas sonoras, ou seja, motivos, frases, períodos e seções.

Os resultados mostraram que a proposta da teoria expressiva de Lussy fornece dados relevantes sobre os processos interpretativos na segunda metade do século XIX. Uma análise com a técnica de Lussy capta bem um estilo de interpretação daquela época, haja vista que a gravação mais antiga analisada (a de Segóvia) se aproxima bastante da teoria dos acentos lussyana. Por outro lado, a gravação mais nova (a de Kayath) mostra um afastamento dessa teoria.

O estilo de performance instrumental de contemporâneos de Lussy buscava uma aproximação com a intepretação vocal, tendo como característica a proeminência de cada palavra e cada pequena estrutura da obra. Por outro lado, os intérpretes atuais tendem a ressaltar estruturas maiores, finalizações harmônicas a longo prazo e delineamento da forma global.

Portanto, a teoria lussyana pode contribuir para uma efetiva aproximação entre análise e performance, assim como a formação de uma possível metodologia de abordagem da expressividade. Além disso, outras frentes como psicologia, didática e expressão rítmica em Lussy ainda carecem de mais pesquisas. Esperamos que a exploração posterior dessas outras frentes possa nos dar uma visão cada vez mais completa de sua abordagem. 


\section{Referências}

1. Blum, David. 1980. Casals and the Art of Interpretation. Los Angeles: University of California Press.

2. Brendel, Alfred. 1990. Music Sounded Out. New York: Robson Books.

3. Caplin, William. 2008. Theories of Musical Rhythm in the Eighteenth and Nineteenth Centuries. In: The Cambridge History of Western music theory, p. 657694. Cambridge: Cambridge University Press.

4. Clarke, Eric; Cook, Nicholas (eds.). 2004. Empirical musicology: Aims, Methods, Prospects. New York: Oxford University Press.

5. Curwen, Spencer. 1878. On the Laws of Musical Expression, as Formulated by Lussy in His “Traité de l'Expression Musicale'. In: Royal Music Association, 4th session, p. 27-48. England: Taylor \& Francis.

6. Dogantan-Dack, Mine. 2002. Mathis Lussy: A pioneer in studies of expressive performance. Bern: Peter Lange.

7. . 2012. Phrasing the Very Life of Music: Performing the Music and Nineteenth-century Performance Theory. In: Nineteenth-century music review, p. 7-30. Cambridge: Cambridge University Press.

8. Fabian, D.; Timmers, R.; Schubert, E. 2014. Expressiveness in Music Performance: Empirical Aproaches Across Styles and Cultures. Oxford: Oxford University Press.

9. Freire, Sérgio, et al. 2012. O Som Plaqué no Violão: Aspectos Qualitativos e Quantitativos em Situação Musical. In: IV Seminário Música Ciência Tecnologia. p. 125-132.

10. Gabrielsson, Alf. 1987. The Theme from Mozart's Piano Sonata in A major K.331: a Comparison of Five Performances. In: Action and Perception in Rhythm and Music, p. 81-103. Stockholm: Royal Swedish Academy of Music.

11. Huray, Peter; Day, James. 1981. Music and Aesthetics in the Eighteenth and EarlyNineteenth Centuries. London: Cambridge University Press.

12. Huron, David. 2006. Sweet Anticipation: Music and the Psychology of Expectation. Cambridge, MA: MIT Press.

13. Kayath, Marcelo. 1993. Guitar Favourites. 1 CD. UK: IMP Classics.

14. Lussy, Mathis. 1874. Traité de l'Expression Musicale: Accents, Nuances et Mouvements dans la Musique Vocal et Instrumentale. Paris: Berger-Levrault \& Heugel. 
MUSICA THEORICA Revista da Associação Brasileira de Teoria e Análise Musical 2018, v. 3, n. 2, p. 227-257 - Journal of the Brazilian Society for Music Theory

15. and Analysis @ TeMA 2018 - ISSN 2525-5541

15. 1882. Musical Expression: Accents, Nuances, and Tempo, in Vocal and Instrumental Music. London: Novello\&Ewer.

16. 1883. Le Rythme Musical: son Origine, sa Fonction et son Accentuation. Paris: Heugel.

17. . 1885. Die Correlation zwischen Takt und Rhythmus. Vierteljahsschrift für Musikwissenschaft. Leipzig: Breitkopf und Härtel.

18. __ 1903. L'Anacrouse dans la Musique Moderne. Paris: Heugel.

19. . 1912. La Sonate Pathétique de L. Van Beethoven, op.13: Rythmée at Annotée par Mathis Lussy. Paris: Costallat.

20. Repp, Bruno. 1990. Patterns of Expressive Timing in Performances of a Beethoven Minuet by Nineteen Famous Pianists. Journal of the Acoustical Society of America, v. 88, n.2, p. 622-641.

21. _ 1992. A Constraint on the Expressive Timing of Melodic Gesture: Evidence from Performance and Aesthetic Judgment. Music Perception, n. 10, p. 221-242.

22. Rothstein, William. 1989. Phrase Rhythm in Tonal Music. New York: Schimer.

23. Russel, David. 1991. Francisco Tárrega: Integral de Guitarra. 2 CDs. Spain: Opera Tres.

24. Schenker, Heinrich. 2000. The Art of Performance. (Ed. Heribert Esser) ou A Arte da Performance (trad. Irene Schreier); (Original: Die Kunst des Vortrag). Oxford: Oxford University Press.

25. Segóvia, Andrés. 1956. Masters of the Guitar: Compositions of Sor and Tárrega. 1LP. USA: Decca.

26. Silva, Felipe A. V. 2017. A Lógica e o Processo da Escuta Riemanniana. In: Anais do $13^{\circ}$ Simpósio Internacional de Cognição e Artes Musicais, Curitiba, p. 220228.

27. Todd, Neil. 1985. A Model of Expressive Timing in Tonal Music. Music Perception, v.3, n.1, p. 33-58. 